\title{
Complexation of Uranium(VI) by Gluconate in Acidic Solutions: Thermodynamic Study with Structural Analysis
}

Zhicheng Zhang, ${ }^{\mathrm{a}, \mathrm{c}}$ Gregory Helms, ${ }^{\mathrm{b}}$ Sue B. Clark, ${ }^{\mathrm{a}, *}$ Guoxin Tian, ${ }^{\mathrm{c}}$ PierLuigi Zanonato, ${ }^{\mathrm{c}, \mathrm{d}}$ and Linfeng Rao ${ }^{\mathrm{c}, *}$

${ }^{a}$ Chemistry Department, Washington State University, Pullman, WA 99164, U.S.A. Email:s_clark@wsu.edu

${ }^{b}$ Center for NMR Spectroscopy, Washington State University, Pullman, WA 99164, U.S.A. ${ }^{c}$ Lawrence Berkeley National Laboratory, Berkeley, CA 94720, U.S.A. E-mail: LRao@lbl.gov

${ }^{d}$ Dipartimento di Scienze Chimiche, Università di Padova, via Marzolo 1, 35131, Padova, Italy

Abstract
Within the $\mathrm{p} C_{\mathrm{H}}$ range of 2.5 to 4.2 , gluconate forms three uranyl complexes, $\left(\mathrm{UO}_{2}\left(\mathrm{GH}_{4}\right)^{+}, \mathrm{UO}_{2}\left(\mathrm{GH}_{3}\right)(\mathrm{aq})\right.$ and $\mathrm{UO}_{2}\left(\mathrm{GH}_{3}\right)\left(\mathrm{GH}_{4}\right)^{-}$, through the following reactions: (1) $\mathrm{UO}_{2}{ }^{2+}+\mathrm{GH}_{4}^{-}=\mathrm{UO}_{2}\left(\mathrm{GH}_{4}\right)^{+},(2) \mathrm{UO}_{2}{ }^{2+}+\mathrm{GH}_{4}{ }^{-}=\mathrm{UO}_{2}\left(\mathrm{GH}_{3}\right)(\mathrm{aq})+\mathrm{H}^{+}$, and (3) $\mathrm{UO}_{2}{ }^{2+}+$ $2 \mathrm{GH}_{4}^{-}=\mathrm{UO}_{2}\left(\mathrm{GH}_{3}\right)\left(\mathrm{GH}_{4}\right)^{-}+\mathrm{H}^{+}$. Complexes were inferred from potentiometric, calorimetric, NMR, and EXAFS studies. Correspondingly, the stability constants and enthalpies were determined to be $\log \beta_{1}=2.2 \pm 0.3$ and $\Delta H_{1}=7.5 \pm 1.3 \mathrm{~kJ} \cdot \mathrm{mol}^{-1}$ for reaction (1), $\log \beta_{2}=-(0.38 \pm 0.05)$ and $\Delta H_{2}=15.4 \pm 0.3 \mathrm{~kJ} \mathrm{~mol}^{-1}$ for reaction (2), and $\log \beta_{3}=1.3 \pm 0.2$ and $\Delta H_{3}=14.6 \pm 0.3 \mathrm{~kJ} . m o l^{-1}$ for reaction (3), at $I=1.0 \mathrm{M} \mathrm{NaClO}_{4}$ and $t=25{ }^{\circ} \mathrm{C}$. The $\mathrm{UO}_{2}\left(\mathrm{GH}_{4}\right)^{+}$complex forms through the bidentate carboxylate binding to $\mathrm{U}(\mathrm{VI})$. In the $\mathrm{UO}_{2}\left(\mathrm{GH}_{3}\right)(\mathrm{aq})$ complex, hydroxyl-deprotonated gluconate $\left(\mathrm{GH}_{3}{ }^{2-}\right)$ coordinates to $\mathrm{U}(\mathrm{VI})$ through the five-membered ring chelation. For the $\mathrm{UO}_{2}\left(\mathrm{GH}_{3}\right)\left(\mathrm{GH}_{4}\right)^{-}$complex, multiple coordination modes are suggested. These results are discussed in the context of trivalent and pentavalent actinide complexation by gluconate. Key word: actinides, f-element, coordination chemistry, $\alpha$-hydroxy carboxylate ligands, radioactive waste

\footnotetext{
*Corresponding authors: s_clark@wsu.edu,LRao@lbl.gov
} 


\section{Introduction}

The complexation behavior of actinides by $\alpha$-hydroxy carboxylate ligands such as gluconic acid has recently been a renewed subject of study due to the need to process high-level radioactive wastes (HLW) currently stored in million gallon tanks at the Hanford site (Richland, WA). Gluconate was added in large quantities to the nuclear materials processed at Hanford to facilitate dissolution of iron and aluminum ${ }^{1-9}$, and consequently, it directly affects f-element speciation in HLW. ${ }^{10-13}$ This complicates waste processing for vitrification. Despite its use in industrial-scale nuclear materials processing, molecular-level information on the interactions of gluconate and actinide cations has not yet been reported. This lack of data makes it difficult to predict its impact on the behavior of actinides in subsequent waste treatment processes.

In this work, gluconic acid refers to $D$-gluconic acid derived from natural $D$-glucose. To be consistent with the notations in the literature, gluconic acid is, as shown in Scheme

Scheme I

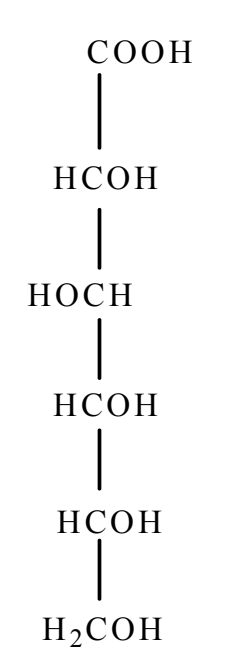

Gluconic acid

$\left(\mathrm{HGH}_{4}\right)$
I, denoted by $\mathrm{HGH}_{4}$, where the first $\mathrm{H}$ refers to the carboxylic acid hydrogen and $\mathrm{H}_{4}$ refers to the four hydrogens on the secondary alcohols. ${ }^{1,2}$ The six carbon atoms are numbered from the top in Glycolic acid ( $\mathrm{HGH})$ order as $\mathrm{C} 1$ to $\mathrm{C} 6$. For the purpose of comparison, glycolic acid and acetic acid were referred to and their structures shown in Scheme I. In the notation of glycolic acid (HGH), the first $\mathrm{H}$ refers to the carboxylic acid hydrogen and the last $\mathrm{H}$ refers to the hydrogen on the alcohol. 
Hexavalent uranium as the $\mathrm{UO}_{2}{ }^{2+}$ ion was studied due to its presence in the HLW tanks at Hanford. Under oxidizing conditions, this is the expected $\mathrm{U}$ oxidation state, and study of uranyl can serve as a chemical model for other hexavalent actinides, such as plutonium. We focused our studies on the low $\mathrm{p} C_{\mathrm{H}}$ range to avoid the complication of uranyl hydrolysis. However, these conditions present another technical challenge: under acidic conditions, gluconic acid undergoes the coupled reactions of lactonization and protonation. Fortunately, these coupled reactions are well described by our earlier work. ${ }^{14}$

In that study, we systematically investigated the solution speciation of gluconic acid over the $\mathrm{p} C_{\mathrm{H}}$ range from 1.0 to 13.0. In acidic solutions, gluconic acid undergoes lactonization after deprotonation of the carboxylate group to form $\gamma$ - and $\delta$-lactones. ${ }^{14,15}$ Gluconic acid lactonization and its reverse reaction, lactone hydrolysis, have been found to proceed more slowly than protonation/deprotonation. Consequently, we determined the deprotonation constant of gluconic acid by measuring ${ }^{13} \mathrm{C}$ chemical shifts as a function of $\mathrm{p} C_{\mathrm{H}}{ }^{14}$ evaluated the equilibrium constant of lactonization by "batch" potentiometric titrations, ${ }^{14}$ and measured the thermodynamic properties of protonation by fast potentiometric titrations and calorimetry at relatively high $\mathrm{p} C_{\mathrm{H}}(>2.5) .{ }^{16}$

Uranyl complexation by gluconate was investigated by Sawyer et al. in the 1960's. ${ }^{11}$ Using light absorption and polarographic measurements, they evaluated the stoichiometry and the formation constants of uranyl gluconate complexes in the $\mathrm{p} C_{\mathrm{H}}$ range of 4.0 to 12.0 . However, due to the unavailability of advanced techniques to characterize the coordination modes at the time, they were not able to directly observe the structures of the complexes. Also, based on experimental observation of slow absorbance 
changes for uranyl/gluconate solutions over a period of weeks, they believed that complexation was unusually slow. However, they did not consider the possibility of reaction or degradation of the ligand and its complexes through lactonization of other means. Since their work four decades ago, little study of uranium complexation by gluconate has appeared in the literature, except for the work of Warwick et al. for gluconate complexation of tetravalent $\mathrm{U}^{13}$ Therefore, the primary objectives of this study are: (1) to obtain reliable thermodynamic data for the complexation of gluconate with uranyl at $I=1.0 \mathrm{M}$ and $t=25^{\circ} \mathrm{C}$, and (2) to obtain structural information on the resulting uranyl gluconate complexes. Thermodynamic parameters were determined by potentiometry and calorimetry. NMR and EXAFS were used, in conjunction with the thermodynamic data, to establish the coordination details in the complexes.

\section{Experimental Section}

All chemicals were reagent grade or higher. Distilled and deionized water (18 $\mathrm{M} \Omega$, Milli-Q water system) was used in preparations of all the solutions except those for NMR experiments. In all experiments, precautions were taken to avoid the exposure of uranyl/gluconate samples to laboratory light unless specifically mentioned by wrapping vials in Al foil. The stock solution of uranyl perchlorate was prepared by dissolving uranium trioxide $\left(\mathrm{UO}_{3}\right)$ in perchloric acid (Sigma-Aldrich, Inc.). The concentration of uranium in the stock solution was determined by absorption spectrophotometry and fluorimetry. ${ }^{17}$ Gran's potentiometric method ${ }^{18}$ was used to determine the concentration of perchloric acid in the stock solutions. Volumetric standard sodium hydroxide solutions (Brinkmann Instruments, Inc., or Sigma-Aldrich, Inc.) were verified to be carbonate-free prior to use. The ionic strength of all the solutions used in potentiometry 
and calorimetry was adjusted to $1.0 \mathrm{M}$ at $25^{\circ} \mathrm{C}$ by adding appropriate amounts of sodium perchlorate as the background electrolyte.

Sodium gluconate (Acros) was used as received without further purification. The stock solution of gluconate was prepared by dissolving an appropriate amount of sodium gluconate in water or $99.96 \% \mathrm{D}_{2} \mathrm{O}$ (Cambridge Isotope laboratories) for the $\mathrm{NMR}$ experiments. To minimize the lactonization of gluconic acid during potentiometric and calorimetric titrations, working solutions of gluconate were always freshly prepared by adjusting the acidity of the solution with perchloric acid immediately prior to each titration.

2.1. Potentiometry. The stability constants of gluconate complexation with uranyl were determined by potentiometric titrations at $t=25^{\circ} \mathrm{C}$. A specifically-designed thermostatic cup was used to control the temperature. Details of the titration setup have been provided elsewhere. ${ }^{19,20}$

Electromotive force (EMF, in millivolts) was measured with a Metrohm $\mathrm{pH}$ meter (model 713) equipped with a Ross combination $\mathrm{pH}$ electrode (Orion model 8102). Because potassium perchlorate is much less soluble than sodium perchlorate, precipitation of the former could result in the clogging of the electrode frit glass septum. As a result, the original electrode filling solution (3.0 $\mathrm{M}$ potassium chloride) was replaced with 1.0 $\mathrm{M}$ sodium chloride. The electrode potential (in $\mathrm{mV}$ ) in the acidic

$$
E=E^{0}+\frac{\mathrm{RT}}{\mathrm{F}} \ln \left[\mathrm{H}^{+}\right]+\lambda_{\mathrm{H}}\left[\mathrm{H}^{+}\right]
$$

region can be expressed by equation 1 , where $R$ is the gas constant, $F$ is the Faraday constant, and $T$ is the temperature in Kelvin. The term of $\lambda_{\mathrm{H}}\left[\mathrm{H}^{+}\right]$is an electrode junction potential for hydrogen. Prior to each complexation titration, an acid/base titration with 
standard perchloric acid and sodium hydroxide solutions was performed to obtain $E^{\circ}$ and $\lambda_{\mathrm{H}}$. These parameters allowed the calculation of hydrogen ion concentrations from the electrode potential in the subsequent titration.

Multiple titrations were conducted with initial solutions of different $\mathrm{UO}_{2}\left(\mathrm{ClO}_{4}\right)_{2}$ and $\mathrm{HClO}_{4}$ concentrations. The complexation constants of uranyl/gluconate on the molarity scale were calculated with the program Hyperquad. ${ }^{21}$ The protonation constant of gluconic acid $\left(\log K_{\mathrm{a}}=3.3 \pm 0.1\right)$, determined previously, ${ }^{16}$ was used in these calculations. Reported uncertainties represent the composite uncertainties associated with the errors from calibration, potentiostat measurements, and those introduced by the calculations (e.g., Hyperquad).

2.2. Calorimetry. The enthalpy of gluconate complexation with uranyl was determined by calorimetric titrations on a solution calorimeter (model ISC-4285, Calorimetry Sciences Corp). The details of the calorimeter were provided previously. ${ }^{19}$ The performance of the calorimeter was tested by measuring the enthalpy of protonation of tris(hydroxymethyl)-aminomethane (THAM). The measured value, $-47.7 \pm 0.3$ $\mathrm{kJ} \cdot \mathrm{mol}^{-1}$ at $25^{\circ} \mathrm{C}$, compared well with those in the literature. ${ }^{19,22}$

Multiple titrations were conducted with different concentrations of $\mathrm{UO}_{2}\left(\mathrm{ClO}_{4}\right)_{2}$ and $\mathrm{HClO}_{4}$ at $25{ }^{\circ} \mathrm{C}$. For each titration run, $n$ experimental values of the total heat produced in the reaction vessel $\left(Q_{\mathrm{ex}, j}, j=1-n\right)$ were calculated as a function of the mass of the added titrant. These values were corrected for the heat of dilution of the titrant $\left(Q_{\mathrm{dil}, j}\right)$, which was determined in separate runs. The net reaction heat at the $j$ th point $\left(Q_{\mathrm{r}, j}\right)$ was obtained from the difference $Q_{\mathrm{r}, j}=Q_{\mathrm{ex}, j}-Q_{\mathrm{dil}, j}$. A quantity, $\Delta h_{\mathrm{v}, \mathrm{M}}$, defined as the total heat per mole of metal (uranium), was calculated by dividing the net reaction heat 
with the number of moles of metal in the calorimeter vessel. The enthalpy of complexation was calculated with the computer program Letagrop ${ }^{23}$ using $\Delta h_{\mathrm{v}, \mathrm{M}}$ as the error-carrying variable. In these calculations, the enthalpy of protonation of gluconate ($4.03 \pm 0.07 \mathrm{~kJ} \mathrm{~mol}^{-1}$ ) determined previously ${ }^{16}$ was used. Similar to the approach used for potentiometry, the reported uncertainties are the propagated errors associated with the uncertainties in calibration, titration, heat measurements, and those introduced by the calculations (e.g., Letagrop).

2.3. NMR spectroscopy. NMR experiments were conducted in the NMR Center of Washington State University (WSU). Various NMR experiments, including ${ }^{1} \mathrm{H},{ }^{13} \mathrm{C},{ }^{1} \mathrm{H}-$ ${ }^{1} \mathrm{H}$ TOCSY and HMQC, were carried out on a Varian Inova 500 Spectrometer. The spectrometer was operated at $499.85 \mathrm{MHz}$ and $125.67 \mathrm{MHz}$ for the measurements of ${ }^{1} \mathrm{H}$ and ${ }^{13} \mathrm{C}$ signals, respectively. The NMR spectra were recorded at a calibrated probe temperature of $22{ }^{\circ} \mathrm{C}$ using the method described in the literature. ${ }^{24}$

Four uranyl/gluconate solutions (I, II, III and IV), containing the same quantity of sodium gluconate but differing amounts of uranyl in $\mathrm{D}_{2} \mathrm{O}$, were prepared for NMR measurements. A small volume of each uranyl/gluconate solution was transferred into a Teflon liner (Norell, Inc) and placed into a NMR tube (Wilmad). All these solutions were measured for ${ }^{1} \mathrm{H}$ and ${ }^{13} \mathrm{C}$ NMR. And among them, only solution II was tested for HMQC and TOCSY.

${ }^{1} \mathrm{H}$ spectra were recorded averaging 200 scans for each spectrum. To minimize the lactonization of gluconic acid, ${ }^{1} \mathrm{H}$ NMR data were collected immediately after the solution was prepared (within 30 minutes, the collection was completed). ${ }^{13} \mathrm{C}$ spectra were recorded averaging $\sim 4500$ scans for each spectrum with continuous decoupling of 
the protons using WALTZ16 decoupling. All spectra were referenced by DSS (sodium 2, 2-dimethyl-2-silapentane-sulfonate), following the procedures reported elsewhere. ${ }^{25,26}$

2D ${ }^{1} \mathrm{H}-{ }^{1} \mathrm{H}$ TOCSY data were collected using the standard Varian pulse sequence with the following acquisition parameters. The spectral width was $2,780 \mathrm{~Hz}$ in both F2 and F1. The data were collected using the States-TPPI hypercomplex method with $128 \mathrm{x}$ 2 increments recorded with a total of 16 scans accumulated per $t_{1}$ increment. Acquisition times were $184 \mathrm{~ms}$ in $\mathrm{t}_{2}$ and $46 \mathrm{~ms}$ in $\mathrm{t}_{1}$. An isotropic mixing time of $50 \mathrm{~ms}$ was used in conjunction with an MLEV-17c windowed mixing sequence, which used a spin locking field of 9.6 KHz. A Z-filter was used at the end of the sequence in conjunction with a 1 ms $20 \mathrm{G} / \mathrm{cm}$ purging pulsed field gradient. The large HOD peak was suppressed with a 200 ms presaturation pulse $\left(\gamma \mathrm{B}_{1}\right.$ field $\left.=75 \mathrm{~Hz}\right)$ following the $1 \mathrm{~s}$ relaxation delay. The data were processed with cosine weighting functions in both dimensions and the $t_{1}$ dimension was extended from 128 real points to 256 real points with linear prediction followed by zero filling and Fourier transformation to give a $2 \mathrm{~K} \times 2 \mathrm{~K}$ real matrix.

The phase sensitive, gradient selected HMQC spectrum was collected using the standard Varian pulse sequence with the following parameters. The spectral width was $2,780 \mathrm{~Hz}$ in $\mathrm{F} 2$ and $5,656 \mathrm{~Hz}$ in F1. The data were collected using the echo-antiecho pulsed field gradient coherence selection with $128 \times 2 t_{1}$ increments collected with 128 scans accumulated for each increment. The relaxation delay was $1 \mathrm{~s}$ and no BIRD or TANGO scheme was used to suppress protons bound to ${ }^{12} \mathrm{C}$. All delays within the pulse sequence were kept short to minimize $\mathrm{T}_{2}$ relaxation losses. Acquisition times were 170 $\mathrm{ms}$ in $\mathrm{t}_{2}$ and $22 \mathrm{~ms}$ in $\mathrm{t}_{1}$ and ${ }^{13} \mathrm{C}$ decoupling was achieved during the acquisition with GARP decoupling. The data were processed with cosine functions in both dimensions 
and the $t_{1}$ data were extended from 128 real points to 256 real points using linear prediction prior to Fourier transformation. The final data matrix was $2 \mathrm{~K} \times 2 \mathrm{~K}$ real points.

The $\mathrm{p} C_{\mathrm{D}}\left(-\log \left[\mathrm{D}^{+}\right]\right)$of each uranyl/gluconate solution was determined from the $\mathrm{pH}$ measurements with a Metrohm pH meter (Model 713) equipped with a Ross combination pH electrode (Orion Model 8102). The electrode was previously calibrated with three standard buffer solutions of $\mathrm{pH} 4.0,7.0$ and 10.0, and then, used to measure the $\mathrm{pH}$ of a uranyl/gluconate solution. The $\mathrm{p} C_{\mathrm{H}}\left(-\log \left[\mathrm{H}^{+}\right]\right)$of the solution was obtained by making the correction on the measured $\mathrm{pH}$ for the "Irving factor" as described in the literature. ${ }^{27}$ Consequently, the $\mathrm{p} C_{\mathrm{D}}$ was calculated using $\mathrm{p} C_{\mathrm{D}}=\mathrm{p} C_{\mathrm{H}}+0.4{ }^{28}$

2.4. Extended X-ray Absorption Fine Structure (EXAFS) Spectroscopy. Three uranyl solutions (XI, XII and XIII) were prepared for EXAFS experiments, based on speciation calculations with the constants of gluconate protonation and uranyl/gluconate complexation at $I=1.0 \mathrm{M} \mathrm{NaClO}_{4}$ and $t=25{ }^{\circ} \mathrm{C}$. Solution XI contains $0.04 \mathrm{M}$ $\mathrm{UO}_{2}\left(\mathrm{ClO}_{4}\right)_{2}$ and $0.80 \mathrm{M} \mathrm{HClO}_{4}$ so that the $\mathrm{U}(\mathrm{VI})$ species is $100 \%$ free $\mathrm{UO}_{2}{ }^{2+}(\mathrm{aq})$. Solutions XII and XIII contain $0.04 \mathrm{M} \mathrm{UO}_{2}\left(\mathrm{ClO}_{4}\right)_{2}$ and different concentrations of gluconate and perchloric acid, with $\mathrm{UO}_{2}\left(\mathrm{GH}_{3}\right)(\mathrm{aq})$ and $\mathrm{UO}_{2}\left(\mathrm{GH}_{3}\right)\left(\mathrm{GH}_{4}\right)^{-}$as dominant species, respectively (Table 2). Approximately $2.2 \mathrm{~mL}$ of the solution was sealed in a polyethylene tube ( $5 \mathrm{~mm}$ i.d.) and mounted on an aluminum sample positioner for the EXAFS experiments.

Uranium $\mathrm{L}_{\mathrm{III}}$-edge EXAFS data were collected at the Stanford Synchrotron Radiation Laboratory (SSRL) on the beamline 11-2 under normal ring operating conditions (3.0 $\mathrm{GeV}, 50-100 \mathrm{~mA}$ ) using $\mathrm{UO}_{2}$ foil as the reference material. Energy scans of the polychromatic X-ray beam were accomplished by using a $\operatorname{Si}(220)$ double-crystal 
monochromator. The vertical slit width was $0.5 \mathrm{~mm}$, which reduced the effects of beam instabilities and monochromator glitches, while providing ample photon flux. The data were collected in transmission mode using argon-filled ionization chambers. To minimize sample exposure to light, only one scan was performed for each sample.

The EXAFS data reduction was performed by standard methods reviewed elsewhere $^{29}$ using the suite of programs EXAFSPAK. The spectra were energycalibrated by simultaneously measuring the spectrum of the reference $\left(\mathrm{UO}_{2}\right)$ and assigning the first inflection point of the $\mathrm{L}_{\mathrm{III}}$ absorption edge of uranium to be $17,166 \mathrm{ev}$. The data reduction included pre-edge background subtraction followed by spline fitting and normalization to extract EXAFS data above the threshold energy, $E_{0}$, defined as $17185 \mathrm{ev}$. The curve fitting analyses were also conducted using EXAFSPAK to fit the raw $k^{3}$-weighted EXAFS data.

The data fit utilized the theoretical phases and amplitudes calculated by the program FEFF7 $^{30}$ with the model compound $\mathrm{UO}_{2}\left(\mathrm{CH}_{3} \mathrm{COO}\right)_{2} \cdot 2 \mathrm{H}_{2} \mathrm{O} \cdot{ }^{31}$ All the interactions included in the fits were derived from the single- or multiple-scattering (SS or MS) paths calculated for this compound. The relevant paths included in the fits are SS U-O $\mathrm{O}_{\mathrm{ax}}$ (axial), SS U-O (equatorial), SS U-C (from bidentate acetate binding) and MS O-U-O (3/4legged path). The amplitude reduction factor, $\mathrm{S} 02$, was held fixed at 0.9 for all of the fits. The shift in threshold energy, $\Delta E_{0}$, was allowed to vary as a global parameter in each of the fits.

\section{Results and Discussion}

3.1. Thermodynamic properties by potentiometry and calorimetry. The stability constants and enthalpies of gluconate complexation with uranyl (Table 1) were 
calculated from the titration data obtained by potentiometry and calorimetry, respectively. Figure 1 shows two representative sets of potentiometric data with different initial $\mathrm{p} C_{\mathrm{H}}$ $\left(\mathrm{p} C_{\mathrm{H}} \sim 3.0\right.$ in Figure 1a, and $\mathrm{p} C_{\mathrm{H}} \sim 2.0$ in Figure 1b.), and Figure 2 gives two representative sets of calorimetric data under similar solution conditions to the potentiometric titrations.

In the experimental $\mathrm{p} C_{\mathrm{H}}$ range (2.0-4.2), gluconic acid is susceptible to lactonization in addition to protonation and complexation. ${ }^{14,15}$ Protonation and complexation are rapid and equilibrium is achieved within seconds, whereas lactonization proceeds slowly. ${ }^{14,15}$ The first-order rate constant of lactonization at $20-22^{\circ} \mathrm{C}$ was determined to be $3.8 \times 10^{-5}$ $\mathrm{s}^{-1}$ at $\mathrm{p} C_{\mathrm{H}} 2.4^{15}$ and $1.7 \times 10^{-5} \mathrm{~s}^{-1}$ at $\mathrm{p} C_{\mathrm{H}} 4.5,{ }^{14}$ corresponding to a reaction time of 7.3 and 16 hrs at $\mathrm{p} C_{\mathrm{H}} 2.5$ and 4.5 , respectively. Based on these kinetic data, the maximum extent of lactonization in 30 minutes is estimated to be $5 \%$ at $\mathrm{p} C_{\mathrm{H}} 2.4$ and $2 \%$ at $\mathrm{p} C_{\mathrm{H}} 4.5$. In previous studies, we have taken advantage of the difference in the kinetics between protonation/complexation and lactonization by conducting rapid potentiometric titrations to determine the gluconate protonation constant ${ }^{16}$ and the $\mathrm{Nd}(\mathrm{III}) /$ gluconate complexation constants $^{32}$ using a fresh gluconate buffer $\left(\mathrm{pC}_{\mathrm{H}}>4.5\right)$ as a titrant. The time interval between data points is 60 seconds, sufficient to achieve steady EMF readings after each addition, and each titration was completed within 30 minutes. Those studies ${ }^{16,32}$ have demonstrated that under such experimental conditions, the effect of lactonization is negligible. Following the same approach, we conducted the potentiometric and calorimetric titrations for the uranyl/gluconate system in this study, and we assume that lactonization is insignificant. The fitting results, as shown in Figures 1 and 2, are 
excellent, suggesting that the lactonization of gluconic acid has little effect on the complexation calculation under the conditions we used.

In the fitting of the potentiometric and calorimetric data, it was necessary to include a deprotonated uranyl complex $\left(\mathrm{UO}_{2}\left(\mathrm{GH}_{3}\right)(\mathrm{aq})\right)$ in the model to achieve a reasonably good fit. This is different from gluconate complexation with $\mathrm{Np}(\mathrm{V})$ (in neutral $\mathrm{p} C_{\mathrm{H}}$ region) ${ }^{16}$ and $\mathrm{Nd}(\mathrm{III})$ (under acidic conditions), ${ }^{32}$ where only the protonated $\mathrm{M}\left(\mathrm{GH}_{4}\right)_{\mathrm{j}}$ complexes $(\mathrm{j}=1-3)$ form. Various combinations of possible species were considered in the fitting, but the best fit was obtained by assuming occurrence of the following three complexation reactions:

$$
\begin{aligned}
& \mathrm{UO}_{2}{ }^{2+}+\mathrm{GH}_{4}{ }^{-}=\mathrm{UO}_{2}\left(\mathrm{GH}_{4}\right)^{+} \\
& \mathrm{UO}_{2}{ }^{2+}+\mathrm{GH}_{4}{ }^{-}=\mathrm{UO}_{2}\left(\mathrm{GH}_{3}\right)(\mathrm{aq})+\mathrm{H}^{+} \\
& \mathrm{UO}_{2}\left(\mathrm{GH}_{3}\right)(\mathrm{aq})+\mathrm{GH}_{4}{ }^{-}=\mathrm{UO}_{2}\left(\mathrm{GH}_{3}\right)\left(\mathrm{GH}_{4}\right)^{-}
\end{aligned}
$$

The calculated stability constants and enthalpies of those complexation reactions are listed in Table 1.

Although these results suggest that three complexation reactions occur, the data fitting alone does not unequivocally reveal coordination modes. However, a comparison of the parameters for other similar ligands complexing with uranyl, or different cations complexed by gluconate, may provide insight into the coordination modes of the uranyl/gluconate system. Therefore, three other cations $\left(\mathrm{Ca}^{2+}, \mathrm{NpO}_{2}{ }^{+}\right.$, and $\left.\mathrm{Nd}^{3+}\right)$ and two other ligands (acetate and glycolate) were introduced into this comparison. The stability constants and enthalpies of gluconate with $\mathrm{Ca}^{2+}, \mathrm{NpO}_{2}{ }^{+}$and $\mathrm{Nd}^{3+}$ were taken from other studies by this group ${ }^{16,32}$ and the complexation thermodynamic properties of glycolate and acetate obtained from the literature. ${ }^{33-35}$ All data refer to $I=1.0 \mathrm{M}$ and $t=25^{\circ} \mathrm{C}$. 
$\mathbf{U O}_{2}\left(\mathbf{G H}_{4}\right)^{+}$complex. It is well recognized that solution complexation of the $f$ elements is electrostatic in nature, which often allows application of simple relationships and trends to predict thermodynamic properties in systems where the coordination geometry of the complexes remains the same. ${ }^{36-38}$ As shown in Fig. 3, complexation of $\mathrm{Ca}^{2+}$ and the tri-, penta-, and hexavalent $f$-elements by acetate follows such a linear trend when the value of the stability constant for the 1:1 complex is plotted as a function of effective cationic charge. However, when a similar approach is used for the gluconate ligand, the magnitude of the stability constant for hexavalent uranium is approximately one order of magnitude lower than expected, suggesting that the coordination chemistry of that complex is not the same for uranyl as compared to the other $f$-element cations.

The nearly linear dioxo configuration of $\mathrm{UO}_{2}{ }^{2+}$ allows coordination to only occur in or near the equatorial plane around the central $\mathrm{U}$ atom. Gluconate, a multifunctional ligand, may form bidentate 1:1 complexes with $\mathrm{U}(\mathrm{VI})$ through a carboxylate group or one carboxylate and one hydroxyl (e.g., $\alpha$-hydroxyl) group. The latter coordination geometry would result in a stronger complex than the former, with the former coordination mode being observed for gluconate complexation with $\mathrm{Ca}^{2+}, \mathrm{NpO}_{2}{ }^{+}$and $\mathrm{Nd}^{3+} \cdot{ }^{16,32}$ For the relationship of the 1:1 stability constant between acetate and these cations (Fig. 3), complexation through the carboxylate group is the same for all the complexes, and the stability constants increase as the charge of the cation increases, including hexavalent uranium. $^{34}$ When comparing the magnitude of the complexation between acetate and gluconate for each of the $\mathrm{Ca}^{2+}, \mathrm{NpO}_{2}{ }^{+}$and $\mathrm{Nd}^{3+}$ cations, the 1:1 stability constant is greater with the gluconate ligand, which results from the participation of the $\alpha$-hydroxyl group with the carboxylate group in the complex. ${ }^{14,16,32}$ Interestingly, the value of the 
1:1 stability constant for the acetate and gluconate complexes with uranyl are approximately the same, providing no increase in complexation that would be expected if the hydroxyl group participated in the ligand coordination to the metal cation. As a result, we believe that the $\mathrm{UO}_{2}\left(\mathrm{GH}_{4}\right)^{+}$complex forms through bidentate carboxylate binding, as observed for the acetate complex, and the $\alpha$-hydroxyl group is not involved in cation binding.

The enthalpy and entropy of formation of the $\mathrm{UO}_{2}\left(\mathrm{GH}_{4}\right)^{+}$complex also support the proposed coordination mode. The complexation of uranyl with simple carboxylates (e.g., acetate) is entropy driven and endothermic (see Table 1), ${ }^{22,34,39}$ resulting from the large energy required for the dehydration of the cation and the anion. For polyhydroxycarboxylic acids (e.g., isosaccharinic acid), the complexation with U(VI) is slightly exothermic, if the hydroxyl group participates in the coordination, due to the less energy required to dehydrate the hydroxyl group than the carboxylate group. ${ }^{19}$ However, the formation of $\mathrm{UO}_{2}\left(\mathrm{GH}_{4}\right)^{+}$, similar to that of $\mathrm{UO}_{2}(\mathrm{~A})^{+}$, is endothermic and entropydriven $\left(\Delta H^{0}=7.5 \pm 1.3 \mathrm{~kJ} \cdot \mathrm{mol}^{-1}\right.$ and $\left.\Delta S^{0}=67 \pm 4 \mathrm{~J} . \mathrm{K}^{-1} \cdot \mathrm{mol}^{-1}\right)$, again suggesting that the hydroxyl group does not bind $\mathrm{UO}_{2}{ }^{2+}$ in this complex.

$\mathrm{UO}_{2}\left(\mathrm{GH}_{3}\right)(\mathrm{aq})$ and $\mathrm{UO}_{2}\left(\mathrm{GH}_{3}\right)\left(\mathrm{GH}_{4}\right)^{-}$complexes. Thermodynamic results indicate that a very strong deprotonated uranyl complex $\left(\mathrm{UO}_{2}\left(\mathrm{GH}_{3}\right)(\mathrm{aq})\right)$ initially forms, followed by the stepwise formation of the $\mathrm{UO}_{2}\left(\mathrm{GH}_{3}\right)\left(\mathrm{GH}_{4}\right)^{-}$complex as more ligand is added. Deprotonation may happen to the hydroxyl group in the ligand or the water coordinated to uranyl, and it is impossible to distinguish them by potentiometry and calorimetry. However, since all thermodynamic experiments were conducted under acidic conditions ( $\mathrm{p} C_{\mathrm{H}} 2.0$ to 4.1 ), we believe that such deprotonation most likely 
happens to the hydroxyl group in gluconate. The two complexes are thus denoted as $\mathrm{UO}_{2}\left(\mathrm{GH}_{3}\right)(\mathrm{aq})$ and $\mathrm{UO}_{2}\left(\mathrm{GH}_{3}\right)\left(\mathrm{GH}_{4}\right)^{-}$.

Glycolate and gluconate, as indicated from the data of Table 1, form the same pattern of uranyl complexes with comparable stability constants, implying similar coordination modes for both. From the thermodynamic properties, a bidentate 1:1 uranyl gluconate complex $\left(\mathrm{UO}_{2}\left(\mathrm{GH}_{4}\right)^{+}\right)$coordinated through the carboxylate group is suggested. Our result is similar to the observations reported by Szabo et al. for the 1:1 uranyl glycolate complex $\left(\mathrm{UO}_{2}(\mathrm{GH}){ }^{+}\right) \cdot{ }^{33}$ On the basis of information for the coordination modes in the uranyl glycolate complexes, we could reasonably assume that in the $\mathrm{UO}_{2}\left(\mathrm{GH}_{3}\right)(\mathrm{aq})$ complex, gluconate coordinates to uranyl through the deprotonated $\alpha$-hydroxyl oxygen and one of carboxylate oxygens, forming a five-membered chelate ring. For the $\mathrm{UO}_{2}\left(\mathrm{GH}_{3}\right)\left(\mathrm{GH}_{4}\right)^{-}$complex, another gluconate attaches to the deprotonated complex $\left(\mathrm{UO}_{2}\left(\mathrm{GH}_{3}\right)(\mathrm{aq})\right)$ through the bidentate carboxylate binding to uranyl. Interestingly, our NMR and EXAFS data (described below) provide direct evidence for the proposed coordination modes for the complexes $\mathrm{UO}_{2}\left(\mathrm{GH}_{4}\right)^{+}$and $\mathrm{UO}_{2}\left(\mathrm{GH}_{3}\right)(\mathrm{aq})$, but do not fully agree on coordination geometry for the $\mathrm{UO}_{2}\left(\mathrm{GH}_{3}\right)\left(\mathrm{GH}_{4}\right)^{-}$complex. This detail will be discussed in the next sections.

The five membered ring $\mathrm{UO}_{2}\left(\mathrm{GH}_{3}\right)(\mathrm{aq})$ chelate is very stable, shown by the large formation constant $\left(\log K=12.6^{\dagger}\right)$. This formation constant also implies that the $\mathrm{p} K_{\mathrm{a}}$ value of the hydroxyl group was significantly decreased from 13 in free gluconate ${ }^{14}$ to 2.4 in the uranyl complex, due to the complexation with $\mathrm{U}(\mathrm{VI})$.

\footnotetext{
${ }^{\dagger} K=\left[\mathrm{UO}_{2} \mathrm{GH}_{3}(\mathrm{aq})\right] /\left[\mathrm{GH}_{3}{ }^{2-}\right]\left[\mathrm{UO}_{2}{ }^{2+}\right]=\beta \cdot K_{\mathrm{a}}$, where $\beta$ is the stability constant of reaction (3) $(\log \beta=-0.38)$ and $K_{\mathrm{a}}$, is the protonation constant of the alkoxide ion $\left(\mathrm{GH}_{3}{ }^{2-}\right)\left(\log K_{\mathrm{a}},=13\right)$.
} 
3.2. Coordination modes by NMR. In the following discussion, three uranyl gluconate complexes in $\mathrm{D}_{2} \mathrm{O}, \mathrm{UO}_{2}\left(\mathrm{GD}_{4}\right)^{+}, \mathrm{UO}_{2}\left(\mathrm{GD}_{3}\right)(\mathrm{aq})$ and $\mathrm{UO}_{2}\left(\mathrm{GD}_{3}\right)\left(\mathrm{GD}_{4}\right)^{-}$, are represented by complexes 1, 2 and 3, respectively, for convenience. Four uranyl/gluconate solutions (I, II, III and IV) for the NMR measurements were prepared in the same way as those used for potentiometric titrations, in which a gluconate solution was titrated by a uranyl solution. This approach allowed us to use the NMR results to verify our assumptions of speciation that were employed for interpreting the potentiometric data.

The speciation at selected points in the titration was calculated using stability constants determined by potentiometry (see supporting materials, Figure S1). In the calculation, the $\mathrm{D}_{2} \mathrm{O}$ effect was considered for gluconate protonation and water dissociation constants, ${ }^{43,}{ }^{44}$ but it was ignored for the uranyl/gluconate complexation constants. Also, the lactonization equilibrium was not included since the NMR data were collected as rapidly as possible before lactonization became significant.

Solutions I, II, III and IV, as indicated in Figure S1, correspond to the solutions at the titrant volume of $0.0,0.10,0.20,0.30 \mathrm{ml}$, respectively. The calculated $\mathrm{p} C_{\mathrm{D}}$ of those solutions decreases with addition of the uranyl solution, which was further confirmed by the experimental $\mathrm{p} C_{\mathrm{D}}$. We had already demonstrated that the ${ }^{1} \mathrm{H}$ and ${ }^{13} \mathrm{C}$ chemical shifts of gluconate suffer a small displacement with the $\mathrm{p} C_{\mathrm{D}}$ change (cf. supporting materials, Figures $\mathrm{S} 2$ and $\mathrm{S} 3$ ). Therefore, solution I was specifically treated by adjusting the $\mathrm{p} C_{\mathrm{D}}$ of the initial gluconate solution to be similar to that of solution II, making the two solutions comparable for extraction of complexation information. 
The reason for the chemical shift displacement of gluconate with $\mathrm{p} C_{\mathrm{D}}$ is the fast exchange of conjugate gluconate $\left(\mathrm{GD}_{4}^{-}\right)$and protonated gluconate $\left(\mathrm{DGD}_{4}\right)$ through protonation. For each nucleus, this exchange results in coalescence of the two individual resonances. Usually, under such a fast exchange rate, little line broadening occurs and a sharp peak appears. An observed chemical shift of each nucleus is a mole-fraction weighted average of its two resonances, the acid resonance and the base resonance. ${ }^{45}$ Therefore, when referring to those average sharp NMR peaks shown in Figures S2 and S3, free gluconate, gluconate and gluconic acid are used synonymously, unless specifically mentioned.

${ }^{13} \mathrm{C}$ NMR data. Figure 4 shows the ${ }^{13} \mathrm{C}$ NMR spectra of solutions I, II, III and IV. Peak assignments were made on a basis of earlier work. ${ }^{8,14,43}$ The five carbon (except C1) peaks are assigned to $\mathrm{C} 2, \mathrm{C} 4, \mathrm{C} 5, \mathrm{C} 3$ and $\mathrm{C} 6$ carbons in order of increasing field strength. The spectra of the carboxylate carbon (C1) are not included since this peak is simply broadened into the baseline in the presence of $\mathrm{U}(\mathrm{VI})$. Such severe broadening of the carboxylate carbon peak indicates that the carboxylate group participates in the coordination to uranyl. From Figure 4, it is found that the C2 peak was gradually broadened as the uranyl was titrated into the gluconate from solution II to IV. Comparison with the ${ }^{13} \mathrm{C}$ spectra of free gluconate in Figure S2 suggests that this line broadening might be attributed to complexation and furthermore, strongly suggests that the $\alpha$-hydroxyl group plays a role in the complexation. Also, a set of small $\delta$-lactone carbon peaks (labeled as $\mathrm{L}$ ) appeared in solution IV as expected, where the low $\mathrm{p} C_{\mathrm{D}}$ facilitates lactonization. More importantly, the sharp lactone peaks suggests that the lactone does not interact with uranyl. While the ${ }^{13} \mathrm{C}$ spectra gave limited features for 
evaluation of the detailed coordination modes, they clearly indicate that the carboxylate and the $\alpha$-hydroxyl group are involved in the bonding of uranyl and gluconate.

${ }^{1} \mathbf{H}$ and TOCSY NMR data. ${ }^{1} \mathrm{H}$ spectra of solutions I, II, III and IV are shown in Figure 5, and a ${ }^{1} \mathrm{H}-{ }^{1} \mathrm{H}$ TOCSY spectrum of solution II is depicted in Figure 6. The gluconate protons, to be consistent with the convention, are designated by $\alpha, \beta, \gamma, \delta$ and $\varepsilon$ as shown in the inset structure on the top-right corner of Figure 5. In the absence of uranyl, these protons (unbound gluconate) yielded a set of intensive and sharp NMR peaks (Fig. 5, Spectrum I), which were assigned to $\alpha, \beta, \varepsilon_{\mathrm{a}}, \gamma, \delta$ and $\varepsilon_{\mathrm{b}}$ proton in order of the increasing field strength. ${ }^{8,46}$ As the uranyl was added into the gluconate, the proton spectra (Fig. 5, Spectra II-IV) became more complicated. New ${ }^{1} \mathrm{H}$ peaks were generated and their positions were located dramatically downfield. Also, the peaks $\alpha$ and $\beta$ of the unbound set were broadened and shifted downfield a bit. To be distinguished from the unbound set, this set is hereinto labeled as set $\mathrm{X}$ (Fig. 5, Spectra II-IV). The line broadening of the $\alpha$ and $\beta$ peaks in set X may be caused by the exchange of bound and unbound gluconate, whereas their displacement may be attributed to the formation of uranyl gluconate complexes as well as the $\mathrm{pH}$ variation, which has been observed to affect the chemical shift of free gluconate (cf, Figure S3).

While we may confer the appearance of new ${ }^{1} \mathrm{H}$ peaks in the ${ }^{1} \mathrm{H}$ NMR spectra (Figure 5) to the complexation between uranyl and gluconate, we cannot interpret these resonances without additional information. TOCSY and HMQC data allow us to solve this problem. From the ${ }^{1} \mathrm{H}-{ }^{1} \mathrm{H}$ TOCSY data (Figure 6), two new sets of ${ }^{1} \mathrm{H}$ peaks (sets $\mathrm{Y}$ and Z) are well recognized and believed to correspond to two different coordination structures of uranyl gluconate complexes. Assuming that carboxylic and $\alpha$-hydroxyl 
groups of gluconate were involved in the coordination for these structures, the peak assignment (cf, Figure 6) was conducted by referring to the HMQC data in this work and the ${ }^{13} \mathrm{C}-{ }^{13} \mathrm{C}$ TOCSY data of ${ }^{13} \mathrm{C}$ labeled gluconate with uranyl in other work. ${ }^{44}$ It must be noted that we are highly confident in the assignment of protons $\alpha$ and $\beta$ in both sets, where as the assignment of others $(\gamma, \delta, \varepsilon a$ and $\varepsilon b)$ carries less uncertainty.

The coordination modes, proposed by the thermodynamic study, are that gluconate in complex 2 coordinates to $\mathrm{U}(\mathrm{VI})$ through the five-membered ring chelation and gluconate in complex 1 or stepwise gluconate in complex 3 coordinates to U(VI) through bidentate carboxylate binding. The bidentate carboxylate binding gluconate is henceforth named as type $\mathrm{X}$ gluconate and the five-membered ring coordinating gluconate as type $\mathrm{Z}$ gluconate. The protons of type $\mathrm{Z}$ gluconate are expected to experience a dramatic magnetic environmental change due to the deprotonation and coordination of the hydroxyl group. Additionally, slow ligand exchange is supposed to occur in this case since the strong chelation ring forms. Thus, this type of gluconate may give a separate set of ${ }^{1} \mathrm{H}$ NMR peaks. However, the situation of type $\mathrm{X}$ gluconate is the contrary to that of type $\mathrm{Z}$ gluconate. Owing to the small change of magnetic environments and the fast exchange of ligands, the ${ }^{1} \mathrm{H}$ NMR signals of type $\mathrm{X}$ gluconate should emerge with those of unbound gluconate but result in the line broadening of some peaks (e.g., $\alpha$ and $\beta$ protons).

Taking solution II as a start, we evaluate how those NMR data approach the proposed coordination modes. Solution II, as calculated (cf. Figure S1), contains a large amount of gluconate conjugate species ( $70 \%$ free gluconate and $14 \%$ gluconic acid) but only a small amount of complexes (4\% complex 2 and 12\% complex 3 ). With 
consideration of the change in magnetic environment and the slow ligand exchange for type $\mathrm{Z}$ gluconate, it is reasonable to conclude that the set $\mathrm{Z}$ signals (Fig. 5, Spectrum II and Fig. 6) are attributed to type $\mathrm{Z}$ gluconate. It is apparent that the line broadening of the $\alpha$ and $\beta$ peaks in set $X$ (Fig. 5, Spectrum II) is caused by type $X$ gluconate in complex 3. Notice that the similar observation was also obtained in the NMR study of the uranyl glycolate system. ${ }^{33}$ Therefore, the coordination structures proposed from the thermodynamic study are well supported by the ${ }^{1} \mathrm{H}$ signals of sets $\mathrm{X}$ and $\mathrm{Z}$.

However, it is puzzling that no structure proposed from the thermodynamic results corresponds to the signals of set Y. Under the experimental conditions, we believe that two isomers exist with different structures for complex 3. One is of the coordination structure mentioned above, where the second gluconate coordinates to U(VI) through bidentate carboxylate binding. The other is of structure where the second gluconate chelates to U(VI) through the bindings of two oxygen atoms coming from the carboxylic group and the $\alpha$-hydroxyl group, respectively. Obviously, the thermodynamic methods used in this work are unable to discriminate between them. Under the latter coordination mode, both gluconate molecules coordinate to uranyl through the five membered rings, and the only difference between them is the deprotonation of the $\alpha$ hydroxyl group. The gluconate with this coordination mode is named as type Y gluconate. The type Y gluconate exchange rate is expected to decrease once chelated, and thus, a separate set of ${ }^{1} \mathrm{H}$ peaks may be formed. Also, from point of the influence of $\mathrm{U}(\mathrm{VI})$ charge on the magnetic environment of gluconate, the averaged effect on each type $\mathrm{Y}$ gluconate molecule must be weaker than that on the type $\mathrm{Z}$ gluconate molecule, and the displacement of ${ }^{1} \mathrm{H}$ chemical shifts of type $\mathrm{Y}$ gluconate should hence be smaller than 
that of type Z gluconate. Inspection of the NMR data (Fig. 5, Spectrum II and Figure 6) reveals that the set $\mathrm{Y}$ signals match the above two features of type Y gluconate, which indicates that complex 3 may have an isomer with the type $\mathrm{Y}$ coordination mode.

The ${ }^{1} \mathrm{H}$ NMR data of other solutions (solutions III and IV) also support the above analysis results. For example, the speciation calculation results (cf, Figure S1) indicate that as uranyl was added into the gluconate solution, the formation of both complexes 1 and 2 was increased (complex 1: $0.2 \%, 1.2 \%$, and $4 \%$ in solutions II, III and IV, respectively; complex 2: 4\%, 10\% and $15 \%$ in solutions II, III and IV, respectively). Correspondingly, the ${ }^{1} \mathrm{H}$ signals, sets $\mathrm{X}$ and $\mathrm{Z}$, perfectly reflect such a trend. As indicated in Fig. 5 (Spectra II-IV), the $\alpha$ and $\beta$ peaks of set $\mathrm{X}$ were more broadened and displaced more downfield as more complex 1 formed, and the signals of set $\mathrm{Z}$ became more intensified with the increase of formation of complex 2.

Scheme II

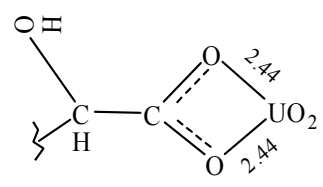

1. $\mathrm{UO}_{2}\left(\mathrm{GH}_{4}\right)^{+}$

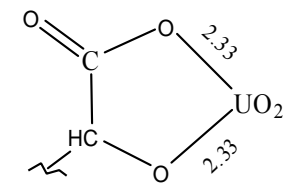

2. $\mathrm{UO}_{2}\left(\mathrm{GH}_{3}\right)(\mathrm{aq})$ (a)

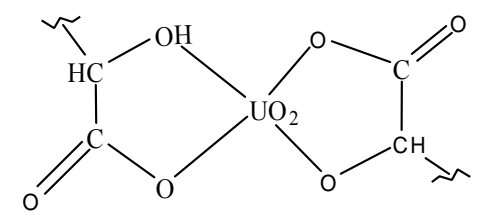

(b)

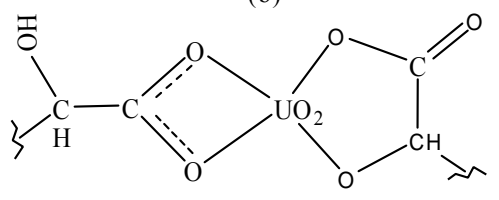

3. $\mathrm{UO}_{2}\left(\mathrm{GH}_{3}\right)\left(\mathrm{GH}_{4}\right)^{-}$

In summary, the NMR data not only confirm the coordination modes for complex 1 and 2 but also point out the possibility of formation of the two isomers for complex 3 . The coordination geometries for these complexes are depicted in Scheme II. The appearance of three sets of ${ }^{1} \mathrm{H}$ NMR signals is thus interpreted as followings: (1) set X 
forms from free gluconate and type $\mathrm{X}$ gluconate in complexes 1 and $3 \mathrm{~b}$; (2) set $\mathrm{Y}$ from type $\mathrm{Y}$ gluconate in complex 3a; (3) set $\mathrm{Z}$ from type $\mathrm{Z}$ gluconate in complexes 2 and $3 \mathrm{~b}$.

3.3. Coordination structures by EXAFS. Figure 7 shows the raw $k^{3}$-weighted EXAFS data and the corresponding Fourier Transform (FT) for $\mathrm{UO}_{2}{ }^{2+}$ in solutions XI, XII and XIII. The theoretical curve fits are also depicted in the figure, and the structural fitting results are summarized in Table 2. The FT represents a pseudoradial distribution function, and the peaks are shifted to lower $\mathrm{R}$ values as a result of the phase shifts associated with the absorber-scatter interactions $(\sim 0.2-0.5 \AA)$. The speciation calculation of those solutions was conducted using the stability constants determined by potentiometry and taking into account the lactonization equilibrium constants $\left(\log K_{\mathrm{L}}=\right.$ 0.54). ${ }^{14}$ The calculated results are also listed in Table 2.

In the absence of gluconate (solution XI), the FT of the free uranyl solution (Fig. 7, Spectrum XI) shows two peaks that arise from the presence of $2 \mathrm{O}_{a x}$ at $1.77 \AA$ and $\sim 6$ $\mathrm{O}_{\mathrm{eq}}$ at $2.41 \AA$. This is consistent with the structural results obtained previously for the fully hydrated uranyl ion. ${ }^{45,46}$ The spectrum of solution XII (Fig. 7) shows a different pattern with a splitting in the $\mathrm{O}_{\mathrm{eq}}$ region, which suggests the $\mathrm{O}_{\mathrm{eq}}$ shell may be divided into two shells. The curve fits confirm the existence of two $\mathrm{O}_{\mathrm{eq}}$ shells as follows: $1.6 \mathrm{O}_{\mathrm{eq} 1}$ at $2.33 \AA$ and $4.5 \mathrm{O}_{\mathrm{eq} 2}$ at $2.44 \AA$. Since the extended $k$ range $\left(2.5-17 \AA^{-1}\right)$ was used in the data collection and analysis, the maximum resolution in radial distance could approach $0.11 \AA$. Thus, the observed difference of the two resolved Oeq shells (difference $=0.11$ $\AA)$ is acceptable. It is important to note that the results represent an average of all possible structures in the solution. The speciation of solution XII indicates a distribution of $10 \%$ complex 3, $40 \%$ complex $2,25 \%$ complex 1 and $25 \%$ free $\mathrm{UO}_{2}{ }^{2+}$. As discussed 
in the NMR section, the three coordination structures, types $\mathrm{X}, \mathrm{Y}$ and $\mathrm{Z}$, are accounted for these complexes. The coordination and hydration structures of uranyl are quantitatively ranked as type $Z$ ( $>40 \%$, complexes 2 and $3 a)$, type $X(>25 \%$, complexes 1 and $3 \mathrm{~b}$ ), hydration $(25 \%)$ and type $\mathrm{Y}(<10 \%$, complex $3 \mathrm{a})$ in the order of increasing fractions. Because the small amount of type $\mathrm{Y}$ is expected to have little effect on the major features of the EXAFS curve, the U- $\mathrm{O}_{\mathrm{eq}}$ shell during the curve fitting may reasonably fall into two categories: a close shell with the type $\mathrm{Z}$ structure and a distant shell with the mixed structures of type $\mathrm{X}$ and hydration. The EXAFS fitting results of solution XII confirm the above hypothesis. As a result, the $\mathrm{O}_{\text {eq1 }}$ shell at $2.33 \AA$ represents the binding oxygens from the gluconate coordinating to $\mathrm{U}(\mathrm{VI})$ through the fivemembered ring chelation in complexes 2 and $3 b$, and the $\mathrm{O}_{\text {eq2 } 2}$ shell at $2.44 \AA$ represents the averaging binding oxygens from the hydration water and the coordinating gluconate through the bidentate carboxylate binding in complexes 1 and $3 b$.

The FT of solution XIII (Fig. 7) shows no splitting feature in the $\mathrm{O}_{\text {eq }}$ region. The speciation calculation indicates that complex 3 is a dominant uranyl gluconate complex $(90 \%)$ in the solution. The fitting results (Table 2) gave a reasonable coordination number $(N=5.7)$ and $\mathrm{U}-\mathrm{O}$ distance $(R=2.38 \AA)$ for the $\mathrm{U}-\mathrm{O}_{\mathrm{eq}}$ shell, but an unusually large Debye-Waller factor $\left(\sigma^{2}=0.012\right)$. This large factor implies that the $\mathrm{U}-\mathrm{O}_{\mathrm{eq}}$ shell may contain multiple shells, or to say, multiple coordination structures. This is consistent with our observations by NMR, e.g., the two isomers may exist for complex 3. Many attempts were made to approach some structural parameters of individual isomers. For example, in the fitting scheme, the $\mathrm{U}-\mathrm{O}_{\mathrm{eq}}$ shell, like that for the solution XII analysis, we considered two sub-shells, which was intended to allow one to represent the average of 
hydration and type $\mathrm{X}$ coordination structure in complex $3 \mathrm{~b}$, and allow the other to represent the average of the type $\mathrm{Y}$ and type $\mathrm{Z}$ structures in complexes $3 \mathrm{a}$ and $3 \mathrm{~b}$. But all of these attempts failed. This failure may suggest that the $\mathrm{U}-\mathrm{O}_{\text {eq }}$ distance in the type $\mathrm{Y}$ structure is not close to either $\mathrm{U}-\mathrm{O}_{\text {eq }}$ distance in the type $\mathrm{X}$ structure or that in the type $\mathrm{Z}$ structure. With the maximum resolution of $0.11 \AA$, resolving those sub-shells is impossible. While the EXAFS analysis of solution XIII could not provide specific structural parameters for individual isomers, it does support the existence of multiple structures for complex 3 .

\section{Conclusions.}

In the $\mathrm{pC}_{\mathrm{H}}$ range of 2.5 to 4.5 , our work indicates that gluconate forms three possible complexes with the uranyl cation, depending on conditions: $\mathrm{UO}_{2}\left(\mathrm{GH}_{4}\right)^{+}$, $\mathrm{UO}_{2}\left(\mathrm{GH}_{3}\right)(\mathrm{aq})$ and $\mathrm{UO}_{2}\left(\mathrm{GH}_{3}\right)\left(\mathrm{GH}_{4}\right)^{-}$. Thermodynamic parameters for these complexes have been determined by potentiometry and calorimetry. The stability constants and enthalpies of corresponding complexation reactions were measured at $I=1.0 \mathrm{M} \mathrm{NaClO}_{4}$ and $t=25^{\circ} \mathrm{C}$. By comparison with the complexation properties of uranyl with glycolate and acetate, coordination modes have been proposed for individual complexes. The complex $\mathrm{UO}_{2}\left(\mathrm{GH}_{4}\right)^{+}$forms through bidentate carboxylate binding to $\mathrm{U}(\mathrm{VI})$. In the complex $\mathrm{UO}_{2}\left(\mathrm{GH}_{3}\right)(\mathrm{aq})$, the $\alpha$-hydroxyl group of gluconate deprotonates and two oxygens from the carboxylic and deprotonated hydroxyl groups attach to U(VI) forming a stable five-membered ring chelation structure. The coordination structure of complex $\mathrm{UO}_{2}\left(\mathrm{GH}_{3}\right)\left(\mathrm{GH}_{4}\right)^{-}$combines the above two modes, e.g., one gluconate coordinates to uranyl through the five-membered ring chelation and the other through the bidentate carboxylate binding. 
The NMR study and the EXAFS analysis strongly support the proposed coordination structures for the complexes $\mathrm{UO}_{2}\left(\mathrm{GH}_{4}\right)^{+}$and $\mathrm{UO}_{2}\left(\mathrm{GH}_{3}\right)(\mathrm{aq})$, but do not fully agree with the structure for the complex $\mathrm{UO}_{2}\left(\mathrm{GH}_{3}\right)\left(\mathrm{GH}_{4}\right)^{-}$. Our NMR results, in particular the ${ }^{1} \mathrm{H}$ NMR and TOCSY data, suggest two different coordination structures with the stoichiometry of $\mathrm{UO}_{2}\left(\mathrm{GH}_{3}\right)\left(\mathrm{GH}_{4}\right)^{-}$, but further work is needed to confirm this.

In the formation of the five-membered ring chelation under acidic conditions, the $\alpha$-hydroxyl group of gluconate deprotonates and coordinates to U(VI) with a large formation constant. This is the first time that such a complexation mechanism is demonstrated unequivocally by multiple spectroscopic methods.

Acknowledgements. At Washington State University, this work was supported primarily by U.S. DOE's Environmental Management Science Program. SBC, ZZ, and GH also acknowledge support from the U.S. Department of Energy, Basic Energy Sciences, Heavy Elements program, contract DE-FG02-06ER15782 for the NMR studies. The work performed at Lawrence Berkeley National Laboratory (LBNL) was supported by U.S. Department of Energy, Office of Science, Office of Basic Energy Sciences under Contract No. DE-AC02-05CH11231 at LBNL. The EXAFS experiments were conducted at SSRL, which is operated by the Department of Energy, Division of Chemical Science. Special thanks are due to Drs. Corwin Booth and Wayne Lukens (LBNL) for their help on the EXAFS analyses in this work.

Supporting Information Available: Figures depicting the the speciation of a titration related to the preparation of uranyl/gluconate solutions for NMR measurement, and the ${ }^{1} \mathrm{H}$ and ${ }^{13} \mathrm{C}$ NMR spectra of gluconate at varying $\mathrm{p} C_{\mathrm{H}}$ can be found in the 
supplementary information accompanying this manuscript. Those materials are available free of charge via the Internet at http://pubs.acs.org.

\section{References}

(1) Pecsok, R. L.; Sandera, J. J. Amer. Chem. Soc. 1955, 77, 1489.

(2) Sawyer, D. T. Chem. Rev. 1964, 64, 633.

(3) Sawyer, D. T.; Brannan, J. R. Inorg. Chem. 1965, 5, 65.

(4) Bodini, M. E.; Sawyer; D. T. J. Amer. Chem. Soc. 1976, 98, 8366.

(5) Good, R.; Sawyer, D. T. Inorg. Chem. 1976, 15, 1427.

(6) Motekaitis, R. J.; Martell, A. E. Inorg. Chem. 1984, 23, 18.

(7) Carper, W. R.; Coffin, D. B. Inorganica Chimica Acta. 1990, 167, 261.

(8) Ramos, M. L.; Calderia, M. M.; Gil, V. M. S. Carbohydrate Research 1997, 304, 97.

(9) Bechtold, T.; Burtscher, E.; Turcanu, A. Chem. Soc., Dalton Trans. 2002, 2683-2688.

(10) Sawyer, D. T.; Ambrose, R. T. Inorg. Chem. 1962, 1, 296.

(11) Sawyer, D. T.; Kula, R. J. Inorg. Chem. 1962, 1, 303.

(12) Giroux, S.; Rubini, P.; Henry, B.; Aury, S. Polyhedron 2000, 19, 1567.

(13) Warwick, P.; Evans, N.; Hall, T.; Vines, S. Radiochim. Acta 2004, 92, 897.

(14) Zhang, Z.; Gibson, P.; Clark, S. B.; Tian, G.; Zanonato, P.; Rao, L. J. Solution Chem. 2007, 36, 1187-1200.

(15) Sawyer, D. T.; Bagger, J. B. J. Amer. Chem. Soc. 1959, 81, 5302.

(16) Zhang, Z.; Clark, S. B.; Tian, G.; Zanonato, P.; Rao, L. Radiochim. Acta 2006, 94, 531.

(17) Sill, C. W.; Peterson, H. E. Anal. Chem. 1947, 19, 646-651. 
(18) Gran, G. Analyst 1952, 77, 661.

(19) Zanonato, P.; Di Bernardo, P.; Bismondo, A.; Liu, G.; Chen, X.; Rao, L. J. Am. Chem, Soc. 2004, 126, 5515.

(20) Rao, L.; Garnov, A. Y.; Rai, D.; Xia, Y.; Moor, R. C. Radiochim. Acta 2004, 92, 575.

(21) Gans, P.; Sabatini, A.; Vacca, A. Talanta. 1996, 43, 1739.

(22) Jiang, J.; Rao, L.; Di Bernardo, P.; Zanonato, P.; Bismondo, A. J. Chem. Soc., Dalton Trans., 2002, 1832.

(23) Arnek, R. Ark. Kemi 1970, 32, 81.

(24) Raiford, D. S.; Fisk, C. L.; Becker, E. D. Anal. Chem. 1979, 51, 2050.

(25) Wishart , D. S.; Bogam, C. G.; Yao, Abildgard, J.; F.; Dyson, H. J.; Oldfield, E. J.; Markley, L.; Sykes, B. D. J. Biomol. NMR 1995, 6, 135.

(26) Wishart, D. S.; and Nip, A. M. Biochem. Cell Bio. 1998, 76, 153.

(27) Irving, H. M.; Miles, M. G.; Pettit, L. D. Anal. Chim. Acta 1967, 38, 475.

(28) Bates, R. G. In Determination of pH, Theory and Practice; John Willey \& Sons:

New York, 1973.

(29) Koningsberger, D. E.; Prins, R. X-ray Absorption: Principles, Applications,Techniques for EXAFS, SEXAFS, and XANES; Wiley-Interscience: New York, 1988.

(30) Zabinsky, S. I.; Rehr, J. J.; Ankudinov, A.; Albers, R. C.; Eller, M. J. Phys. Rev. B 1995, 52, 2995.

(31) Howatson, J.; Grev, D. M.; Morosin, B. J. Inorg. Nucl. Chem. 1975, 37, 1933.

(32) Zhang, Z.; Bottenus, B.; Clark, S. B.; Tian, G.; Zanonato, P.; Rao, L. Journal of Alloys and Compounds 2007, 444-445, 470-476. 
(33) Szabo, Z.; Grenthe, I. Inorg. Chem. 2000, 39, 5036.

(34) Martell, A. E.; Smith, R. M. "NIST Critically Selected Stability constants of Metal Complexes," NIST Standard Reference Database 46 Version 6.0, developed by R. J. Motekaitis, distributed by NIST Standard Reference Data, 2001.

(35) Kirishima, A; Onishi, Y; Sato, N; Tochiyama, O. "Determination of the thermodynamic quantities of uranium(VI)-carboxylate complexes by microcalorimetry". J. Chem. Thermodynamics, doi: 10. 1016/j.jct.2007.03.013 (2007)

(36) Choppin, G. R., "Factors in Ln(III) Complexation", J. Alloys Compounds, 1997, 249(1-2_1-8.

(37) Di Bernardo, P., Zanonato, P., Melchoir, A., Portanova, R., Tolazzi, M., Choppin, G. G., Wang, Z., "Thermodynamic and spectroscopic studies of lanthanides (III) complexation with polyaminds in dimethyl sulfoxide", Inorg. Chem., 2008, 47(3), $1155-1164$.

(38) Buhl, M., Kabrede, H., Diss, R., and Wipff, G., "Effect of hydration on coordination properties of uranyl (VI) complexes. A first principles molecular dynamics study.", J. Am. Chem. Soc., 2006, 128(19) 6357-6368.

(39) Rao, L.; Jiang, J.; Zanonato, P.; Di Bernardo, P.; Bismondo, A.; Garnov, A. Yu. Radiochim. Acta. 2002, 90, 581.

(40) Covington, R. K.; Robinson, R. A.; Bates, R. G. J. Phys. Chem. 1966, 70, 3820.

(41) Li, N. C.; Tang, P.; Mathur, R. J. Phys. Chem. 1961, 65, 1074.

(42) Drago, R. S. In Physical Methods in Chemistry; Saunders: Philadelphia, 1977; pp. 252-253. 
(43) Escander, G. M.; Olivieri, A. C.; Gonzales-Sierra, M.; Frutos, A. A.; Sala, L. F. J. Chem. Soc., Dalton Tran. 1995, 799.

(44) Martin, L. R.; Witty, R.L.P.; Clark, A.; Helms, G. L.; Nash, K. L. "The Nature of Uranyl Gluconate Complexes in Neutral and Alkaline Solutions". Manuscript in preparation for publication.

(45) Aberg, M.; Ferri, D.; Glaser, J.; Grenthe, I. Inorg. Chem. 1983, 22, 3986.

(46) Thompson, H. A.; Brown, G. E., Jr.; Parks, G. A. Am. Mineral. 1997, 82, 483. 
Table 1. Thermodynamic parameters of gluconate complexation with uranyl. $I=1.0 \mathrm{M}$ $\mathrm{NaClO}_{4}$ and $t=25{ }^{\circ} \mathrm{C}$.

\begin{tabular}{|c|c|c|c|c|}
\hline Reaction & $\log \beta( \pm 3 \sigma)$ & $\begin{array}{c}\Delta G^{\circ} \\
\mathrm{kJ} . \mathrm{Mol}^{-1}\end{array}$ & $\begin{array}{c}\Delta H^{\circ}( \pm 3 \sigma) \\
\mathrm{kJ} . \mathrm{mol}^{-1}\end{array}$ & $\begin{array}{l}\Delta S^{\circ}( \pm 3 \sigma) \\
\text { J. } \mathrm{K}^{-1} \cdot \mathrm{mol}^{-1}\end{array}$ \\
\hline \multicolumn{5}{|l|}{ Uranyl with gluconate } \\
\hline $\mathrm{UO}_{2}{ }^{2+}+\mathrm{GH}_{4}^{-}=\mathrm{UO}_{2}\left(\mathrm{GH}_{4}\right)^{+}$ & $2.2 \pm 0.3$ & -12.6 & $7.5 \pm 1.3$ & $67 \pm 4$ \\
\hline $\mathrm{UO}_{2}^{2+}+\mathrm{GH}_{4}^{-}=\mathrm{UO}_{2}\left(\mathrm{GH}_{3}\right)(\mathrm{aq})+\mathrm{H}^{+}$ & $-(0.38 \pm 0.05)$ & 2.20 & $15.4 \pm 0.3$ & $44 \pm 1$ \\
\hline $\mathrm{UO}_{2}^{2+}+2 \mathrm{GH}_{4}^{-}=\mathrm{UO}_{2}\left(\mathrm{GH}_{3}\right)\left(\mathrm{GH}_{4}\right)^{-}+\mathrm{H}^{+}$ & $1.3 \pm 0.2$ & -7.4 & $14.6 \pm 0.3$ & $74 \pm 1$ \\
\hline \multicolumn{5}{|l|}{ Uranyl with glycolate $^{\mathrm{a}}$} \\
\hline $\mathrm{UO}_{2}^{2+}+\mathrm{GH}^{-}=\mathrm{UO}_{2}(\mathrm{GH})^{+}$ & 2.38 & & $5.6 \pm 0.1$ & \\
\hline $\mathrm{UO}_{2}^{2+}+\mathrm{GH}^{-}=\mathrm{UO}_{2}(\mathrm{G})(\mathrm{aq})+\mathrm{H}^{+}$ & $-(1.26 \pm 0.07)$ & & & \\
\hline $\mathrm{UO}_{2}^{2+}+2 \mathrm{GH}^{-}=\mathrm{UO}_{2}(\mathrm{G})(\mathrm{GH})^{-}+\mathrm{H}^{+}$ & $0.19 \pm 0.09$ & & & \\
\hline \multicolumn{5}{|l|}{ Uranyl with acetate $^{b}$} \\
\hline $\mathrm{UO}_{2}^{2+}+\mathrm{A}^{-}=\mathrm{UO}_{2}(\mathrm{~A})^{+}$ & $2.43 \pm 0.03$ & -13.9 & $11 \pm 1$ & $84 \pm 3$ \\
\hline $\mathrm{UO}_{2}^{2+}+2 \mathrm{~A}^{-}=\mathrm{UO}_{2}(\mathrm{~A})_{2}(\mathrm{aq})$ & $4.43 \pm 0.06$ & -25.3 & $18 \pm 1$ & $148 \pm 4$ \\
\hline $\mathrm{UO}_{2}^{2+}+3 \mathrm{~A}^{-}=\mathrm{UO}_{2}(\mathrm{~A})_{3}^{-}$ & $6.45 \pm 0.07$ & -36.8 & $16 \pm 1$ & $178 \pm 4$ \\
\hline
\end{tabular}

a The stability constants and enthalpy of uranyl complexation with glycolate are from Refs. (33) and (35), respectively.

$\mathrm{b}$ The thermodynamic parameters of uranyl complexation with glycolate and acetate come from and Ref. (34). 
Table 2. U LIII EXAFS structure results for the uranyl complexes with gluconate

\begin{tabular}{|c|c|c|c|c|c|c|c|}
\hline Solution & Speciation $^{\text {a }}$ & Shell & $N^{\mathrm{b}}$ & $\begin{array}{l}R^{\mathrm{b}} \\
(\AA)\end{array}$ & $\begin{array}{c}\sigma^{2} \\
\left(\AA^{2}\right)\end{array}$ & $\begin{array}{l}\Delta E^{0} \\
(\mathrm{ev})\end{array}$ & $F$ \\
\hline XI & $\begin{array}{l}0.04 \mathrm{M} \mathrm{U}_{(\mathrm{VI})}, 0.8 \mathrm{M} \mathrm{HClO}_{4} \\
100 \% \mathrm{UO}_{2}{ }^{+}\end{array}$ & $\begin{array}{l}\mathrm{U}-\mathrm{O}_{\mathrm{ax}} \\
\mathrm{U}-\mathrm{O}_{\text {eq }}\end{array}$ & $\begin{array}{l}2.0 \\
6.3\end{array}$ & $\begin{array}{l}1.77 \\
2.41\end{array}$ & $\begin{array}{l}0.0025 \\
0.0075\end{array}$ & -10.7 & 0.18 \\
\hline XII & $\begin{array}{l}0.04 \mathrm{M} \mathrm{U}(\mathrm{VI}), 0.05 \mathrm{M} \mathrm{HGH}_{4} \\
C_{\mathrm{L}} / C_{\mathrm{U}}=1 / 1, \mathrm{p} C_{\mathrm{H}}=2.8 \\
40 \% \mathrm{UO}_{2}\left(\mathrm{GH}_{3}\right) \\
25 \% \mathrm{UO}_{2}\left(\mathrm{GH}_{4}\right)^{+} \\
25 \% \mathrm{UO}_{2}{ }^{2+} \\
10 \% \mathrm{UO}_{2}\left(\mathrm{GH}_{3}\right)\left(\mathrm{GH}_{4}\right)^{-}\end{array}$ & $\begin{array}{l}\mathrm{U}-\mathrm{O}_{\mathrm{ax}} \\
\mathrm{U}-\mathrm{O}_{\mathrm{eq} 1} \\
\mathrm{U}-\mathrm{O}_{\mathrm{eq} 2} \\
\mathrm{U}-\mathrm{C}\end{array}$ & $\begin{array}{l}2.0 \\
1.6 \\
4.5 \\
1.6\end{array}$ & $\begin{array}{l}1.77 \\
2.33 \\
2.44 \\
3.31\end{array}$ & $\begin{array}{l}0.0025 \\
0.0050 \\
0.0075 \\
0.0050\end{array}$ & -11.5 & 0.19 \\
\hline XIII & $\begin{array}{l}0.04 \mathrm{M} \mathrm{U}(\mathrm{VI}), 0.3 \mathrm{M} \mathrm{HGH}_{4} \\
C_{\mathrm{L}} / C_{\mathrm{U}}=7 / 1, \mathrm{p} C_{\mathrm{H}}=4.2 \\
90 \% \mathrm{UO}_{2}\left(\mathrm{GH}_{3}\right)\left(\mathrm{GH}_{4}\right)^{-} \\
10 \% \mathrm{UO}_{2}\left(\mathrm{GH}_{3}\right)\end{array}$ & $\begin{array}{l}\mathrm{U}-\mathrm{O}_{\mathrm{ax}} \\
\mathrm{U}-\mathrm{O}_{\mathrm{eq}} \\
\mathrm{U}-\mathrm{C}\end{array}$ & $\begin{array}{l}2.0 \\
5.7 \\
4.1\end{array}$ & $\begin{array}{l}1.79 \\
2.38 \\
3.27\end{array}$ & $\begin{array}{l}0.0029 \\
0.012 \\
0.0057\end{array}$ & -10.5 & 0.22 \\
\hline
\end{tabular}

${ }^{a}$ The $\mathrm{p} C_{\mathrm{H}}$ values and $\mathrm{U}(\mathrm{VI})$ species distributions are calculated in terms of the stability constants determined by potentiometry.

${ }^{\mathrm{b}}$ Those values were estimated by EXAFSPAK with the $95 \%$ confidence limits. Solution XI: $\mathrm{U}-\mathrm{O}_{\mathrm{ax}}, R \pm 0.003 \AA, N=2.0$ held constant; $\mathrm{U}-\mathrm{O}_{\mathrm{eq}}, R \pm 0.01 \AA, N \pm 0.80$. Solution XII: $\mathrm{U}-\mathrm{O}_{\mathrm{ax}}, R \pm 0.003 \AA, N=2.0$ held constant; $\mathrm{U}-\mathrm{O}_{\text {eq } 1}, R \pm 0.02 \AA, N \pm 0.50$; $\mathrm{U}-\mathrm{O}_{\text {eq } 2}, R \pm$ $0.03 \AA, N \pm 0.80 ; \mathrm{U}-\mathrm{C}, R \pm 0.04 \AA, N$ linked to U-O $\mathrm{O}_{\text {eq } 1}$. Solution XIII: U-O $\mathrm{O}_{\mathrm{ax}}, R \pm 0.006$ $\AA, N=2.0$ held constant; $\mathrm{U}-\mathrm{O}_{\text {eq }}, R \pm 0.01 \AA, N \pm 0.90 ; \mathrm{U}-\mathrm{C}, R \pm 0.03 \AA, N \pm 0.70$. 

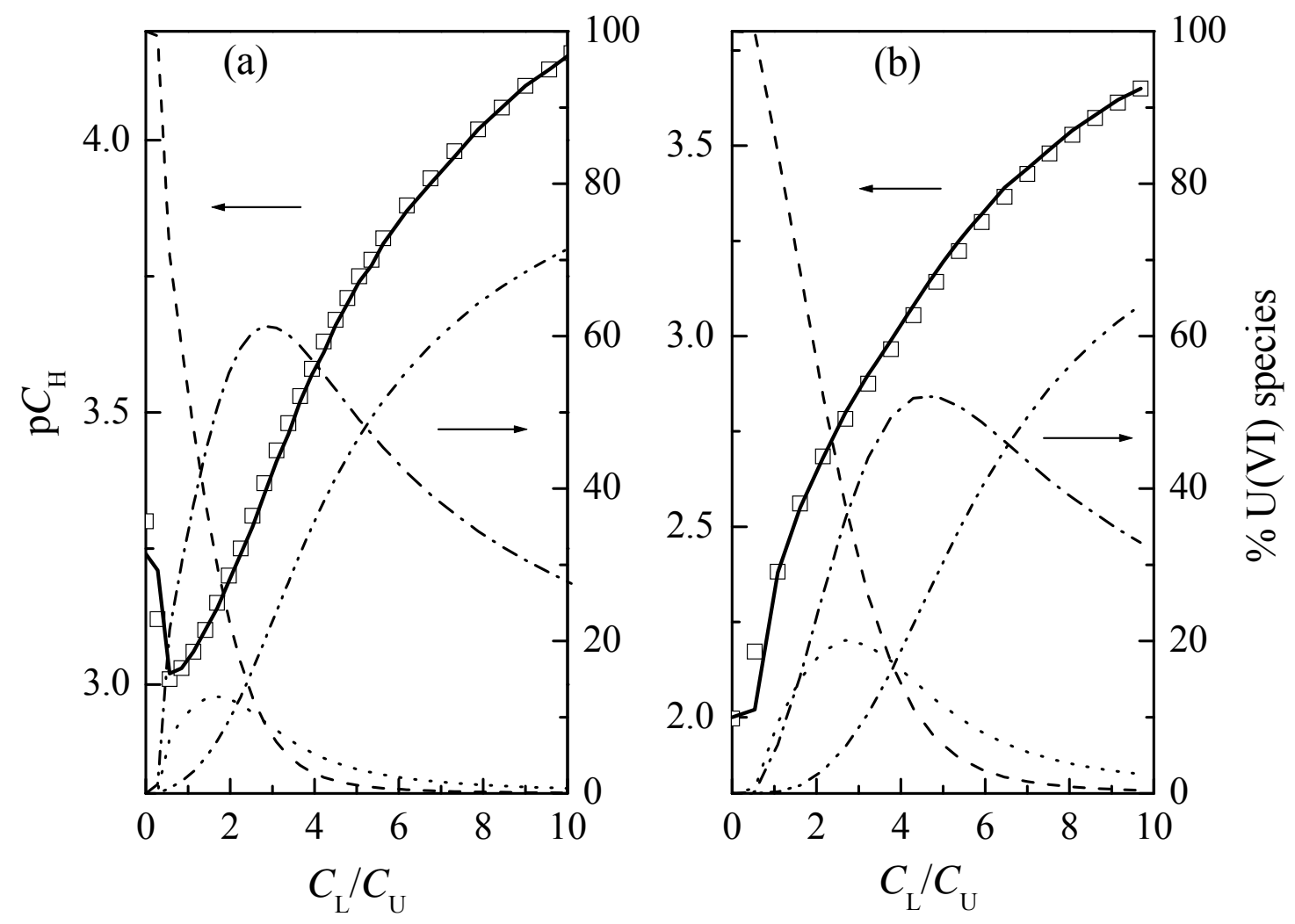

Figure 1. Potentiometric titrations of uranyl with gluconate. $t=25^{\circ} \mathrm{C}, I=1.0 \mathrm{M} \mathrm{NClO}_{4}$. Cup solutions: Titration (a) $-V^{0}=21.20 \mathrm{~mL}, C_{\mathrm{U}}{ }^{0}=0.008349 \mathrm{M}, \mathrm{C}_{\mathrm{H}}{ }^{0}=0.0005755 \mathrm{M}$; Titration (b) $-V^{0}=21.00 \mathrm{~mL}, C_{\mathrm{U}}{ }^{0}=0.008429 \mathrm{M}, C_{\mathrm{H}}{ }^{0}=0.01010 \mathrm{M}$. Titrant: titration (a) $C_{\mathrm{L}}=0.9960 \mathrm{M}, C_{\mathrm{H}}=0.004906 \mathrm{M}$; titration (b) $-C_{\mathrm{L}}=0.9524 \mathrm{M}, C_{\mathrm{H}}=0.04776 \mathrm{M}$. For both titration (a) and (b), symbol $(\square)$ - experimental $\mathrm{p} C_{\mathrm{H}}$ and solid lines - fitted $\mathrm{p} C_{\mathrm{H}}$. In each titration, the dash line, dotted line, dash dot line and dash dot dot line represent the calculated percentages of $\mathrm{UO}_{2}{ }^{2+}, \mathrm{UO}_{2}\left(\mathrm{GH}_{4}\right)^{+}, \mathrm{UO}_{2}\left(\mathrm{GH}_{3}\right)(\mathrm{aq})$ and $\mathrm{UO}_{2}\left(\mathrm{GH}_{3}\right)\left(\mathrm{GH}_{4}\right)^{-}$, respectively. 

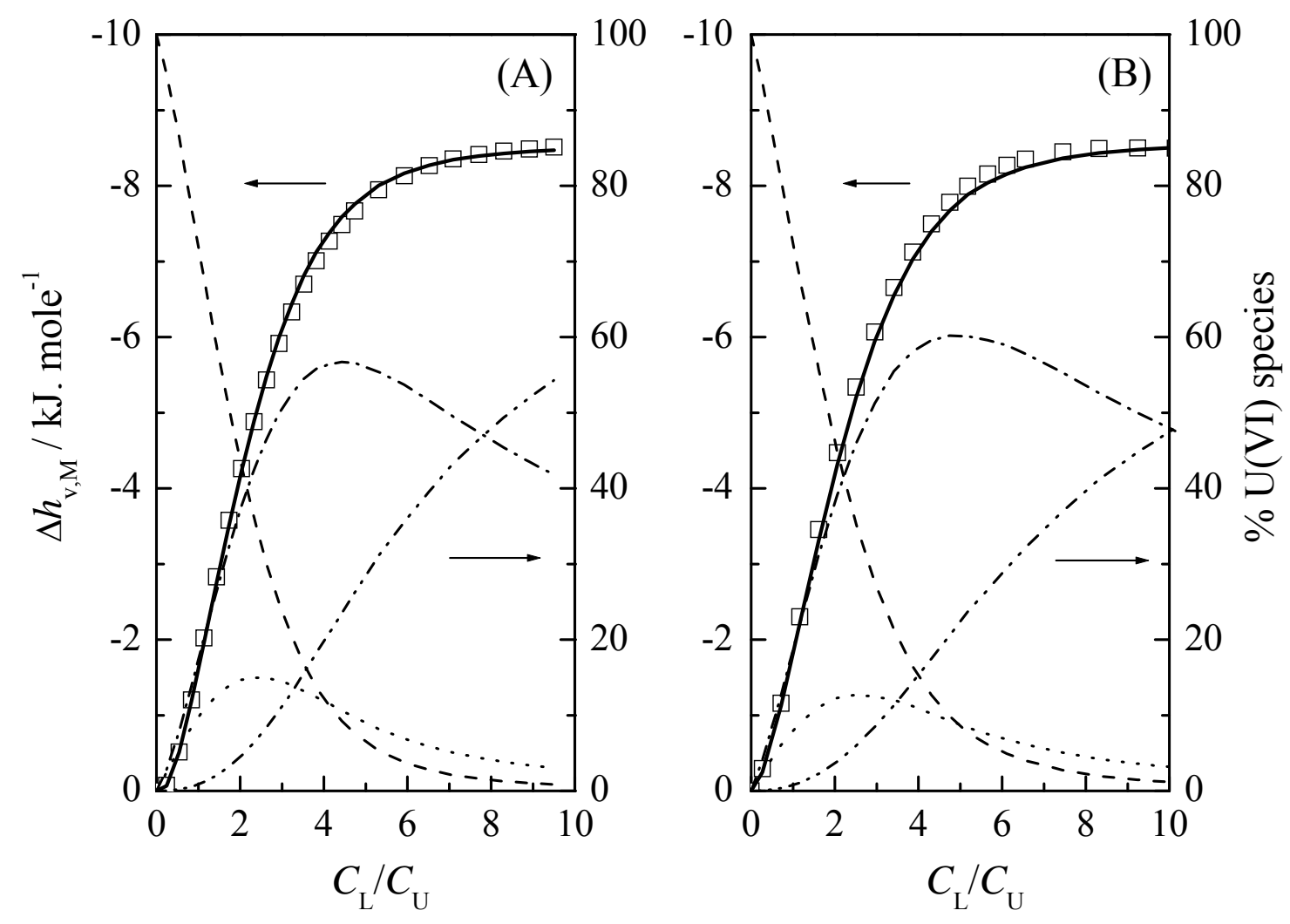

Figure 2. Calorimetric titrations of uranyl with gluconate. $t=25^{\circ} \mathrm{C}, I=1.0 \mathrm{M} \mathrm{NClO}_{4}$. Cup solutions: $V^{0}=0.900 \mathrm{~mL}$; Titration $(\mathrm{A})-C_{\mathrm{U}}{ }^{0}=0.00354 \mathrm{M}, C_{\mathrm{H}}{ }^{0}=0.00224 \mathrm{M}$; Titration (B) $-C_{\mathrm{U}}{ }^{0}=0.00236 \mathrm{M}, C_{\mathrm{H}}{ }^{0}=0.00149 \mathrm{M}$. Titrant: $C_{\mathrm{L}}=0.191 \mathrm{M}, C_{\mathrm{H}}=0.00939$ M. For both titration (A) and (B), symbol ( $\square$ ) - experimental $\Delta h_{\mathrm{v}, \mathrm{M}}$ and solid lines fitted $\Delta h_{\mathrm{v}, \mathrm{M}}$. In each titration, the dash line, dotted line, dash dot line and dash dot dot line represent the percentages of $\mathrm{UO}_{2}{ }^{2+}, \mathrm{UO}_{2}\left(\mathrm{GH}_{4}\right)^{+}, \mathrm{UO}_{2}\left(\mathrm{GH}_{3}\right)(\mathrm{aq})$ and $\mathrm{UO}_{2}\left(\mathrm{GH}_{3}\right)\left(\mathrm{GH}_{4}\right)^{-}$, respectively, which are calculated in terms of the stability constants determined from the potentiometric titrations. 


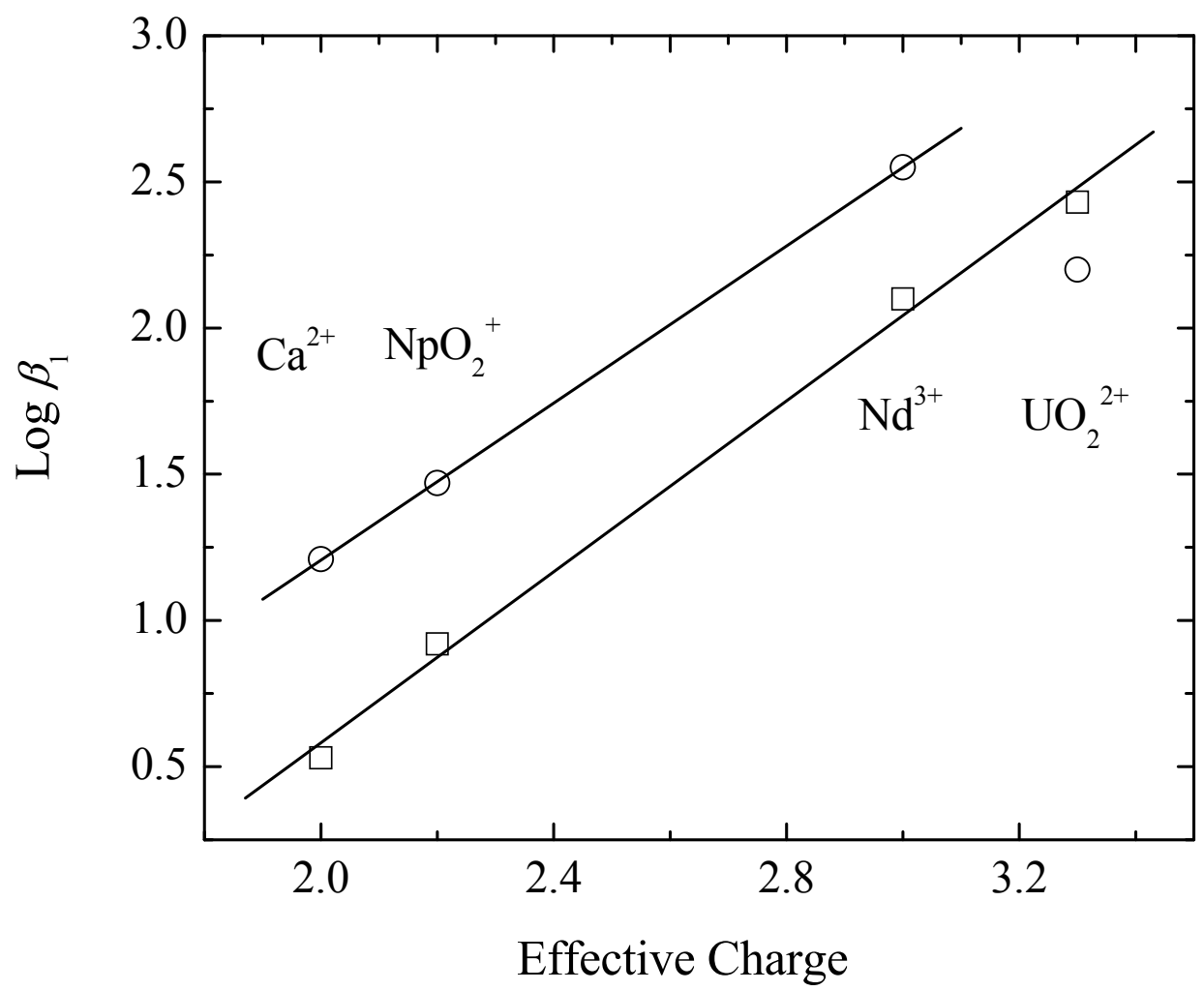

Figure 3.Log $\beta_{1}$ versus effective cationic charge plot. Symbol ( $\square$ ): Data of acetate complexation with those cations at $I=1.0 \mathrm{M}$ and $t=25^{\circ} \mathrm{C}$, obtained from the literature (34); (O): Data of gluconate complexation with those cations at $I=1.0 \mathrm{M} \mathrm{NaClO}_{4}$ and $t$ $=25^{\circ} \mathrm{C}$, determined by this group. 

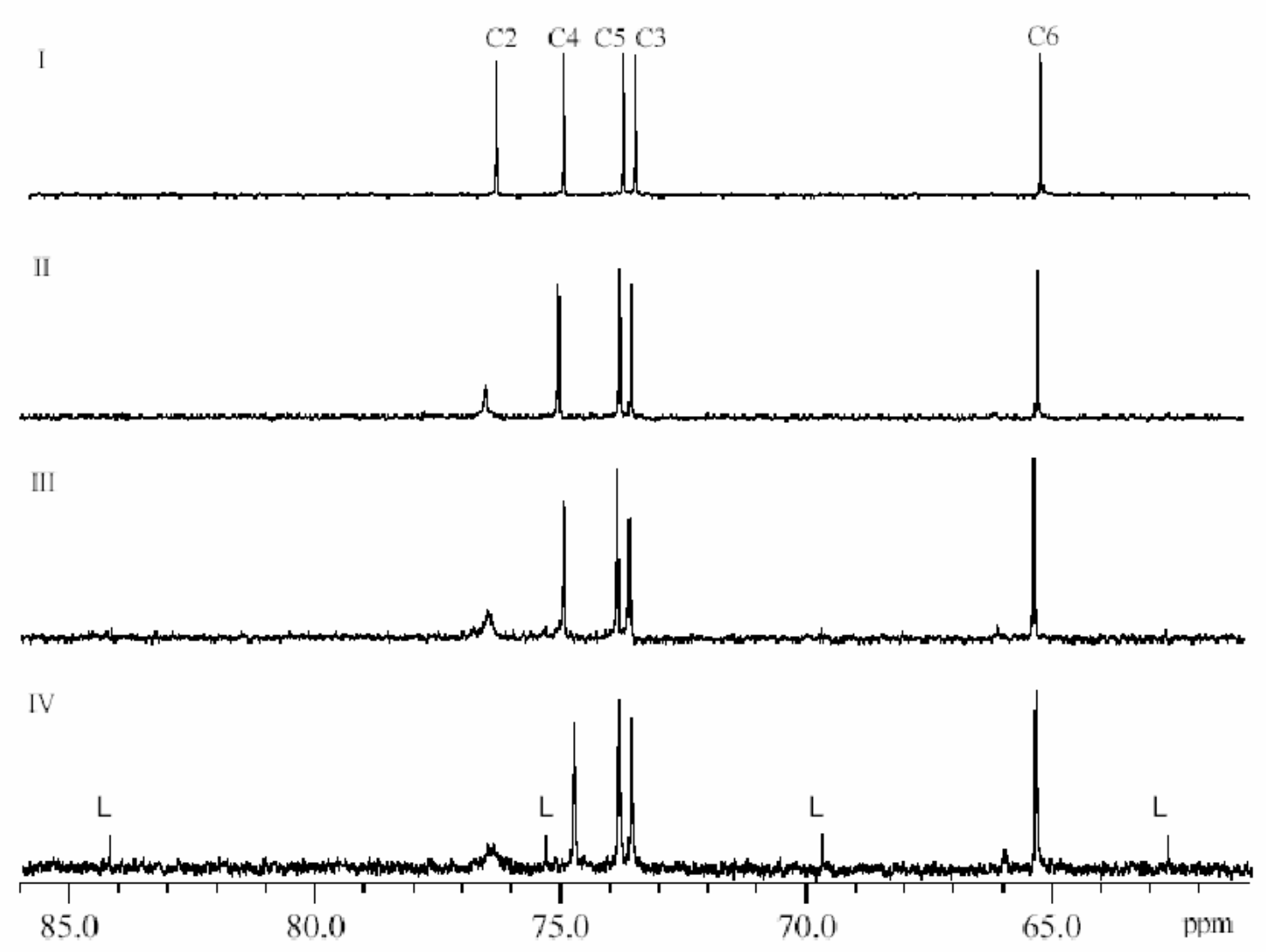

Figure $4 .{ }^{13} \mathrm{C}$ NMR spectra of uranyl/gluconate solutions. $t=22{ }^{\circ} \mathrm{C}$. Spectra I, II, III and IV were taken for solutions I, II, III and IV, respectively. Solutions (I - IV) correspond to the following series of the titration solutions: Cup solution: $V^{0}=11.0 \mathrm{~mL}, C_{\mathrm{L}}{ }^{0}=0.045 \mathrm{M}$, $\mathrm{p} C_{\mathrm{D}}=7.0$; a volume of added uranyl stock solution $\left(0.50 \mathrm{M} \mathrm{U}, 0.20 \mathrm{M} \mathrm{HClO}_{4}\right): 0.0 \mathrm{~mL}$ (instead of adding $0.05 \mathrm{ml} 1.0 \mathrm{M} \mathrm{DCl}, \mathrm{p} C_{\mathrm{D}} 4.50$, solution I), $0.10 \mathrm{~mL}\left(\mathrm{p} C_{\mathrm{D}} 4.45\right.$, solution II), $0.20 \mathrm{~mL}$ ( $\mathrm{p} C_{\mathrm{D}} 3.92$, solution III), $0.30 \mathrm{~mL}$ ( $\mathrm{p} C_{\mathrm{D}} 3.55$, solution IV). 


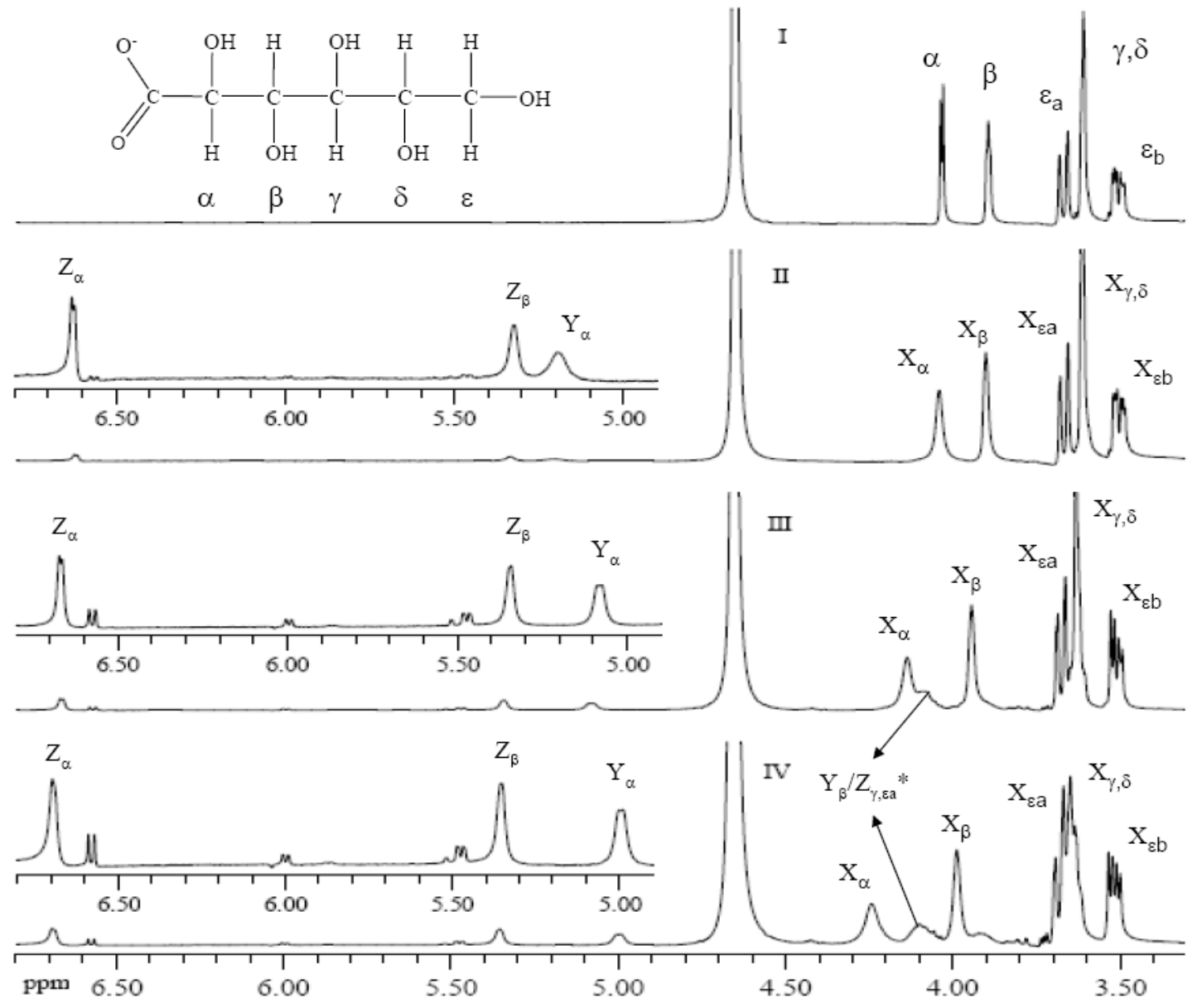

Figure 5. ${ }^{1} \mathrm{H}$ NMR spectra of uranyl/gluconate solutions. Spectra I, II, III and IV were measured for solutions I, II, III and IV, respectively, the same solutions as those used for ${ }^{13} \mathrm{C}$ spectra. The information for those solutions was given in the caption of Figure 4. 


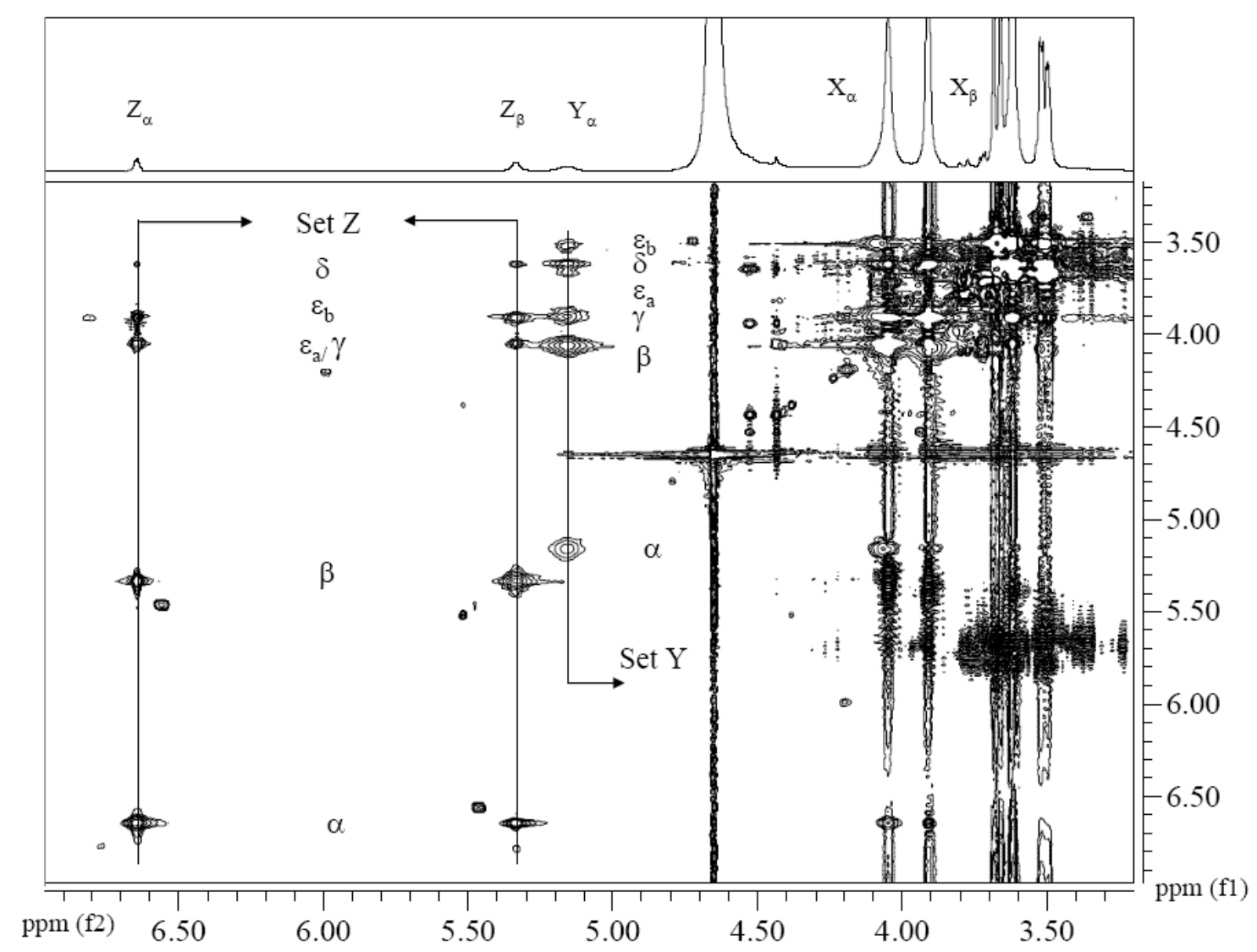

Figure 6. TOCSY NMR spectra of solution II. Data showing the correlations for the $\mathrm{H}_{\alpha}$ and $\mathrm{H}_{\beta}$ of complex labeled $\mathrm{Z}$ and the correlations for the complex labeled $\mathrm{Y}$. 

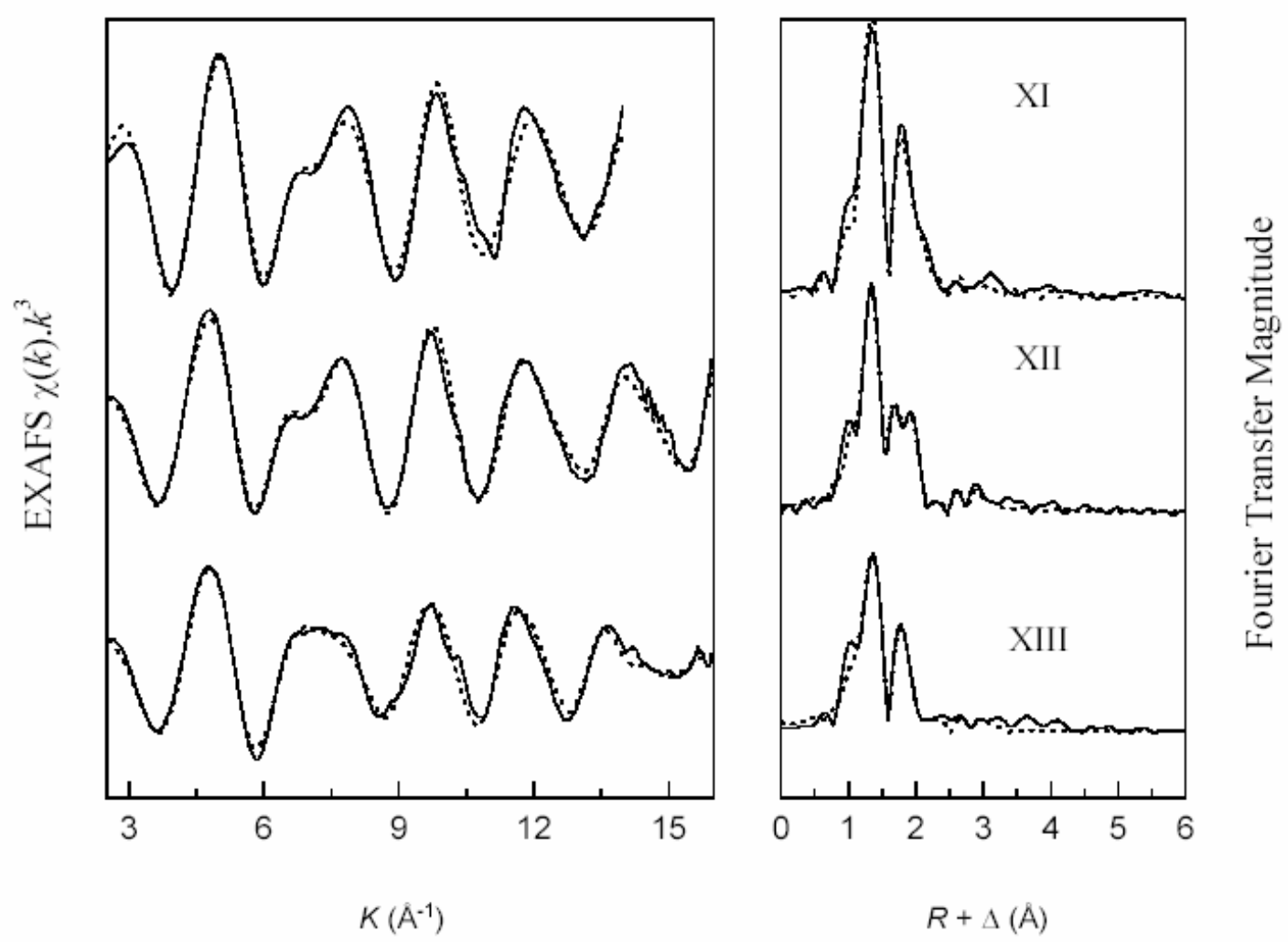

Figure 7. $\mathrm{U}_{\mathrm{III}}$ EXAFS results of uranyl/gluconate solutions. Uranyl stock solution: $C_{\mathrm{U}}=$ $0.18 \mathrm{M}, C_{\mathrm{H}^{+}}=0.21$. Gluconate stock solution: $C_{\mathrm{L}}=1.0 \mathrm{M}, \mathrm{p} C_{\mathrm{H}}=7.0$. The desired volume of each solution $=2.2 \mathrm{~mL}$. The solutions were prepared by the followings: 0.5 $\mathrm{mL}$ uranyl / $1.7 \mathrm{~mL} \mathrm{1.0} \mathrm{M} \mathrm{HClO}_{4}$ (solution XI, $C_{\mathrm{L}} / C_{\mathrm{U}}=0 / 1$ ); $0.5 \mathrm{~mL}$ uranyl $/ 0.05 \mathrm{~mL}$ gluconate (solution XII, $C_{\mathrm{L}} / C_{\mathrm{U}}=1 / 1$ ); $0.5 \mathrm{~mL}$ uranyl / $0.6 \mathrm{~mL}$ gluconate (solution XIII, $C_{\mathrm{L}} / C_{\mathrm{U}}=7 / 1$ ). To each solution vial, $1.0 \mathrm{M} \mathrm{NaClO}_{4}$ was added to reach the desired volume. 


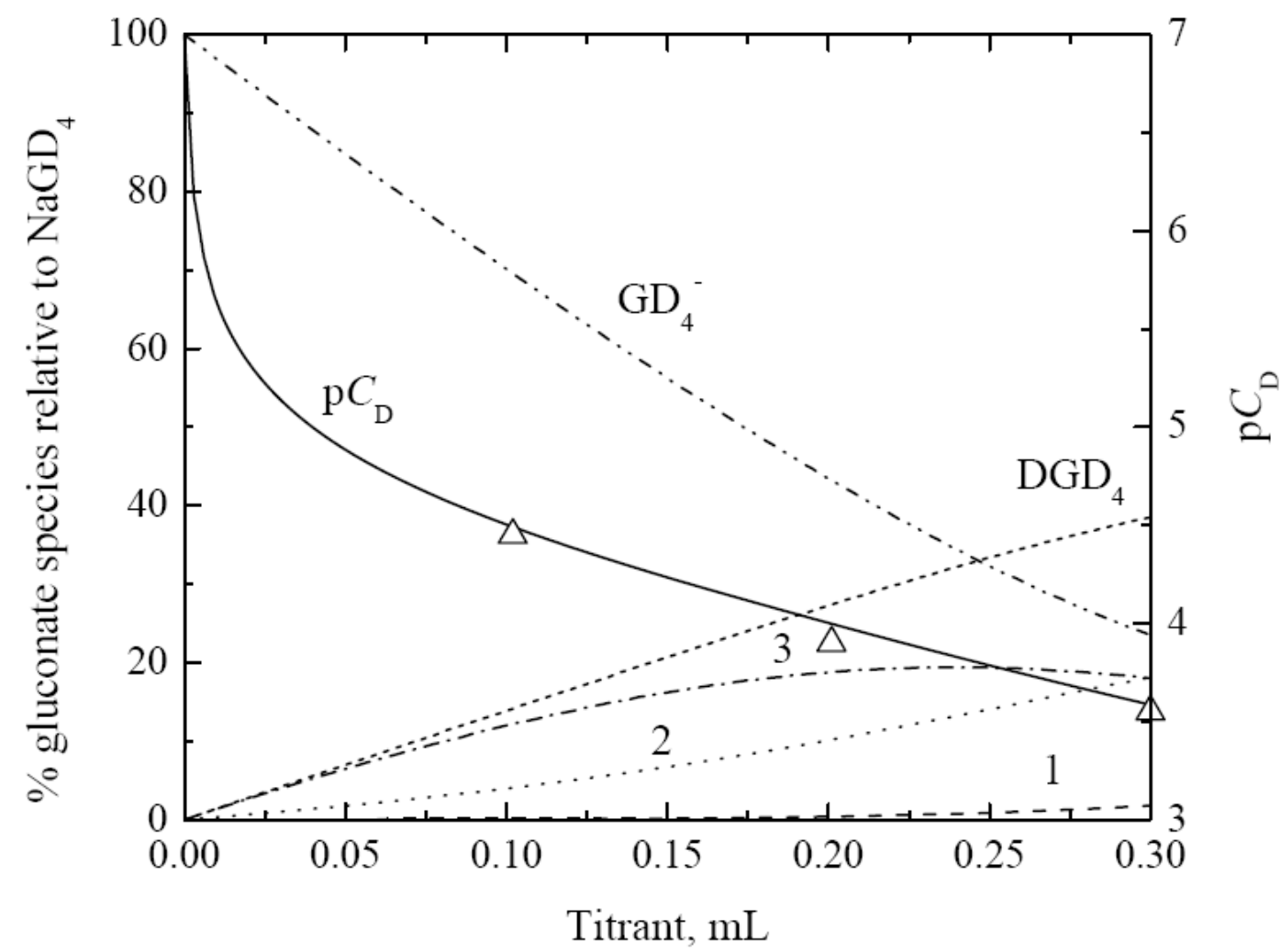

Figure S1. Calculated uranyl/gluconate speciation in terms of the titration conditions for preparing NMR solutions. Cup solution: $V^{0}=11.0, C_{\mathrm{NaGH} 4}{ }^{0}=0.050 \mathrm{M}$; Titrant (uranyl solution): $C_{\mathrm{U}}=0.50 \mathrm{M}, C_{\mathrm{HClO} 4}=0.20 \mathrm{M}$. Numbers 1,2 and 3 indicate complexes 1,2 and 3 , respectively. Symbol $(\Delta)$ : Measured $\mathrm{p} C_{\mathrm{D}}$ of solutions II, III and IV. 

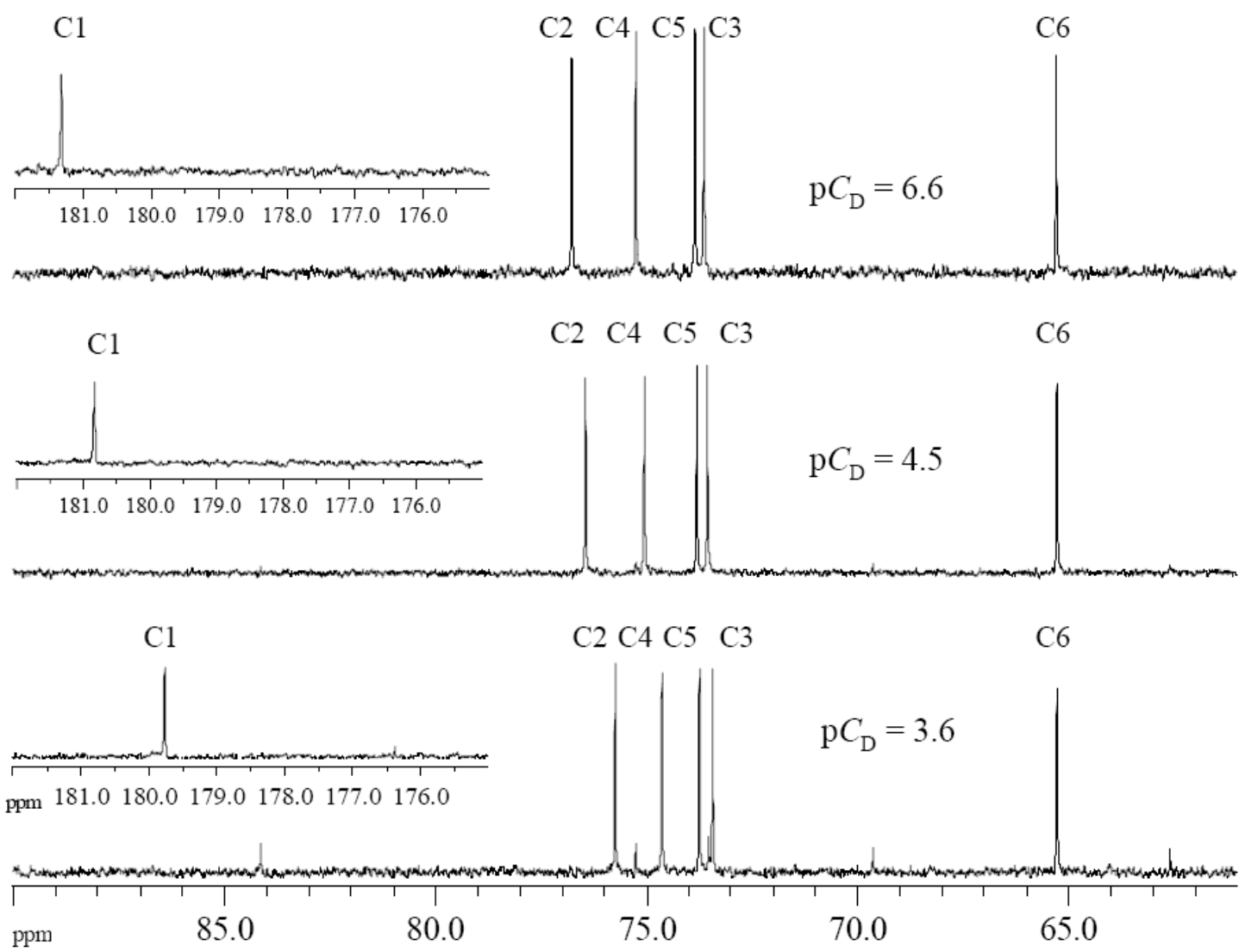

Figure S2. ${ }^{13} \mathrm{C}$ NMR spectra of gluconate solutions at varying $\mathrm{p} C_{\mathrm{D}}$. Varian 300 Spectrometer, $75.5 \mathrm{MHz}, 5000-10000$ scans for individual spectra. $\left[\mathrm{NaGD}_{4}\right]=0.1 \mathrm{M}$, $\mathrm{p} C_{\mathrm{D}}$ of the solutions was adjusted by adding $\mathrm{DCl}$. 


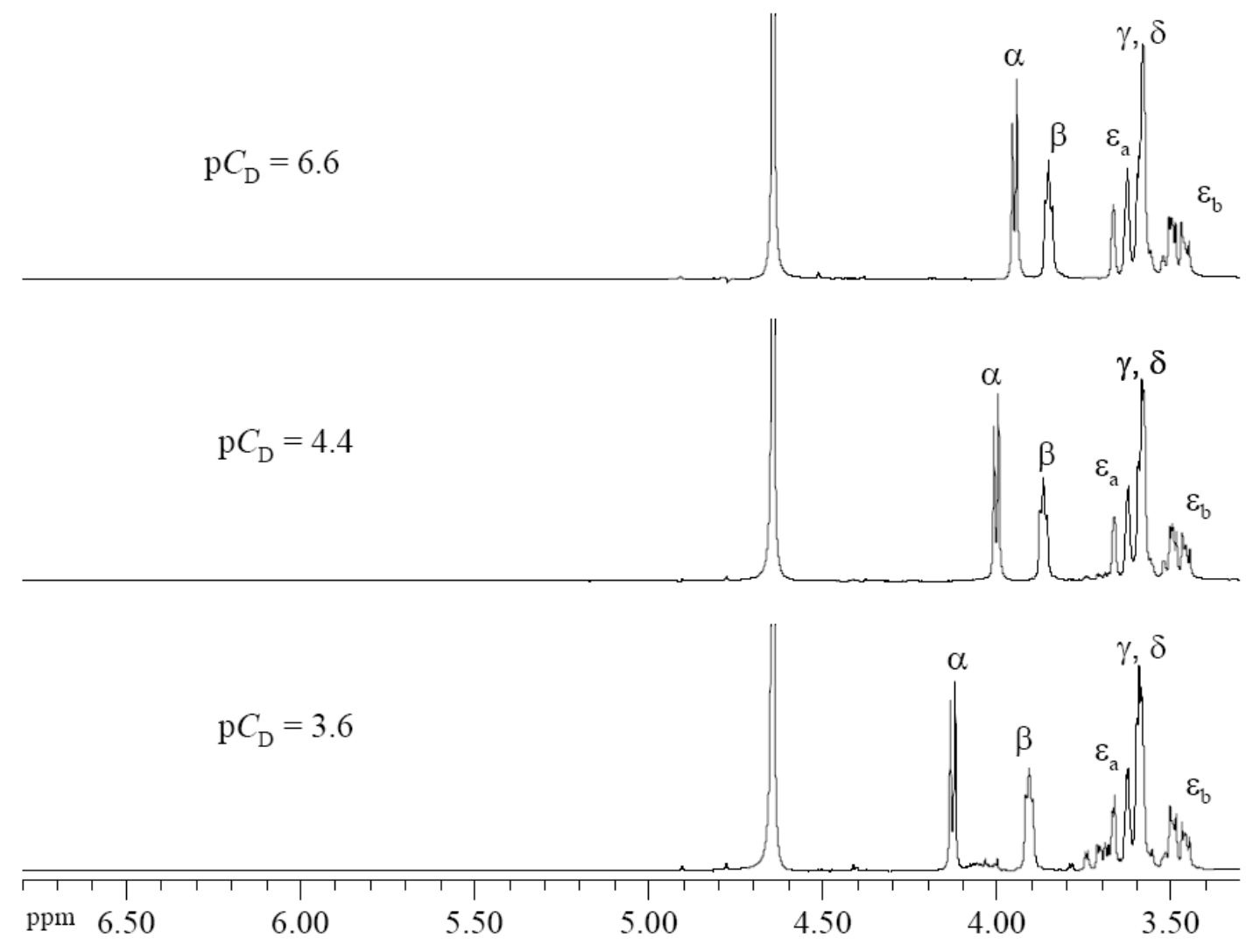

Figure S3. ${ }^{1} \mathrm{H}$ NMR spectra of gluconate solutions at varying $\mathrm{p} C_{\mathrm{D}}$. Varian 300

Spectrometer, $300.1 \mathrm{MHz}, \sim 16$ scans for individual spectra. $\left[\mathrm{NaGD}_{4}\right]=0.1 \mathrm{M}, \mathrm{p} C_{\mathrm{D}}$ of the solutions was adjusted by adding $\mathrm{DCl}$. 